\title{
Climatology, Variability, and Trends in the U.S. Vapor Pressure Deficit, an Important Fire-Related Meteorological Quantity*
}

\author{
RICHARD SEAGER \\ Lamont-Doherty Earth Observatory, Columbia University, Palisades, New York \\ ALLISON HOOKS \\ Columbia College, Columbia University, New York, New York \\ A. PARK WiLliams \\ Lamont-Doherty Earth Observatory, Columbia University, Palisades, New York \\ BENJAMIN COOK \\ NASA Goddard Institute for Space Studies, New York, New York \\ JENNIFER NAKAMURA AND NAOMI HENDERSON \\ Lamont-Doherty Earth Observatory, Columbia University, Palisades, New York
}

(Manuscript received 12 December 2014, in final form 20 March 2015)

\begin{abstract}
Unlike the commonly used relative humidity, vapor pressure deficit (VPD) is an absolute measure of the difference between the water vapor content of the air and its saturation value and an accurate metric of the ability of the atmosphere to extract moisture from the land surface. VPD has been shown to be closely related to variability in burned forest areas in the western United States. Here, the climatology, variability, and trends in VPD across the United States are presented. VPD reaches its climatological maximum in summer in the interior southwest United States because of both high temperatures and low vapor pressure under the influence of the northerly, subsiding eastern flank of the Pacific subtropical anticyclone. Maxima of variance of VPD are identified in the Southwest and southern plains in spring and summer and are to a large extent driven by temperature variance, but vapor pressure variance is also important in the Southwest. La Niña-induced circulation anomalies cause subsiding, northerly flow that drives down actual vapor pressure and increases saturation vapor pressure from fall through spring. High spring and summer VPDs can also be caused by reduced precipitation in preceding months, as measured by Bowen ratio anomalies. Case studies of 2002 (the Rodeo-Chediski and Hayman fires, which occurred in Arizona and Colorado, respectively) and 2007 (the Murphy Complex fire, which occurred in Idaho and Nevada) show very high VPDs caused by antecedent surface drying and subsidence warming and drying of the atmosphere. VPD has increased in the southwest United States since 1961, driven by warming and a drop in actual vapor pressure, but has decreased in the northern plains and Midwest, driven by an increase in actual vapor pressure.
\end{abstract}

\section{Introduction}

In, for the field of meteorology, an unusually passionate polemic, Anderson (1936) argues for measuring and

\footnotetext{
* Lamont-Doherty Earth Observatory Contribution Number 7899
}

Corresponding author address: Richard Seager, Lamont-Doherty Earth Observatory, Columbia University, 61 Rte. 9W, Palisades, NY 10964. E-mail: seager@ldeo.columbia.edu reporting the water vapor content of the atmosphere relative to saturation in terms of vapor pressure deficit (VPD) rather than relative humidity (RH). VPD is the difference between the saturation vapor content of air at temperature $T_{a}, e_{s}\left(T_{a}\right)$, and its actual vapor pressure $e_{a}$, namely,

$$
\mathrm{VPD}=e_{s}\left(T_{a}\right)-e_{a}
$$

whereas $\mathrm{RH}$ is given by their ratio expressed in percent form, namely, 


$$
\mathrm{RH}=100 \times \frac{e_{a}}{e_{s}\left(T_{a}\right)} .
$$

Anderson (1936) points out that RH is not an absolute measure but merely a ratio of two known quantities expressed as a percentage. In contrast, VPD gives an absolute measure of the atmospheric moisture state independent of temperature. For example, for a given wind speed and atmospheric stability, above a surface that is not water limited, a specific VPD leads to the same rate of evaporation, regardless of temperature. Expressing RH and VPD in terms of each other, we get

$$
\begin{aligned}
\mathrm{RH} & =100\left[1-\mathrm{VPD} / e_{s}\left(T_{a}\right)\right] \quad \text { and } \\
\mathrm{VPD} & =e_{s}\left(T_{a}\right)(1-\mathrm{RH} / 100) .
\end{aligned}
$$

In these relations we see the basic problem with $\mathrm{RH}$. For any given RH, the VPD varies exponentially because of the Clausius-Clapeyron dependency of $e_{s}\left(T_{a}\right)$ on $T_{a}$. That is, at very low temperatures a given $\mathrm{RH}$ will correspond to a very small VPD while at high temperatures the same RH will correspond to a very high VPD. Similarly, a given VPD will correspond to a much higher $\mathrm{RH}$ at high temperatures than at lower temperatures. The point of Anderson (1936) was that the water balance stress placed upon an organism is determined by the VPD and not the RH. Despite his arguments, VPD has not exactly caught on. The daily weather forecasts still routinely report RH but never VPD and meteorologists and the public alike are far more familiar with $\mathrm{RH}$ reports, often mentally factoring in the temperature dependence when considering the implications.

Despite the lack of popularity of VPD, it deserves a new lease on life because of its relationship to forest and grassland fire. Fire is an annual concern in many regions of the United States, particularly the western states. Though fire is a naturally occurring phenomenon to which ecosystems are adjusted and, in some cases, even dependent upon, it poses considerable problems for society. First, protection of life has become more difficult as the population of the Southwest has expanded and more people are living at the "urban-forest interface" (Pyne 2009). In addition, damage to property is a concern. Dealing with fire is one of the key problems of land management: How do we manage a process that is at the same time natural and essential and tremendously damaging? Now that western forests are experiencing drought and heat stress combined with outbreaks of bark beetles and unprecedented areas of burns, stresses that are expected to only get worse as human-induced climate change advances (Allen et al. 2010; Bentz et al. 2010; Williams et al. 2013), fire management is ever more important (Stephens et al. 2013). Hence, it is imperative to better understand the processes that control fire.
Many prior studies have sought relationships between climate and wildfire (e.g., Westerling et al. 2003, 2006; Westerling and Bryant 2008; Littell et al. 2009; Abatzoglou and Kolden 2013; Riley et al. 2013). In regard to links between climate and forest fire incidence in the southwestern United States, VPD explains more variance than precipitation, various drought indices, temperature, and wind individually can (Williams et al. 2015). Sedano and Randerson (2014) also found that VPD anomalies were closely related to fire ignition, fire growth, and burned area in Alaska. Potter (2012) provides a useful summary of the research relating fire to atmospheric moisture variables and notes that some early papers did consider aspects of the atmospheric water vapor deficit, though not VPD. For example, one of the very earliest studies of links between fire and weather (Munns 1921) noted a correlation between atmometer evaporation, which will depend strongly on the VPD, and the sizes of fires in southern California. Later, Gisborne (1928) invoked the importance of VPD (without directly mentioning it) when, referring to factors that lead to fires, he stated "A relative humidity of $21 \%$, for example, does not always mean the same rate of drying of the fuel." These combined works over many decades indicate that it is by drying of fuel that high VPD increases fire ignition and growth, as well as the burned area [for more discussion see Potter (2012)].

The importance of VPD is of course a confirmation of Anderson's (1936) plea for the ecological relevance of VPD. It is not surprising that VPD is more successful in explaining burned forest fire area than are other meteorological variables. It is essentially a measure of the ability of the atmosphere to extract moisture from the surface vegetation, thus reflecting variations in the moisture content and flammability of forests. Because it accounts for the fact that it is the combination of low $\mathrm{RH}$ and high temperature that creates the most fire-prone conditions, VPD is more explanatory in this regard than $\mathrm{RH}$. VPD is also more explanatory than temperature (e.g., Westerling et al. 2006) since it reflects the nonlinear dependence of $e_{s}$ on temperature and also measures the actual moisture content of the air, with the combination of high $e_{s}$ and low $e_{a}$ creating the most fireprone conditions. Of course, VPD only indirectly measures the antecedent soil moisture conditions that also influence the current moisture content of vegetation. Hence, it might be expected that preceding precipitation, or an index of current drought severity (such as the Palmer drought severity index, which factors in prior precipitation and estimates of evapotranspiration), would offer additional explanatory power over VPD alone. Consistently, Williams et al. (2014, 2015) found a combination of current VPD and prior-year 


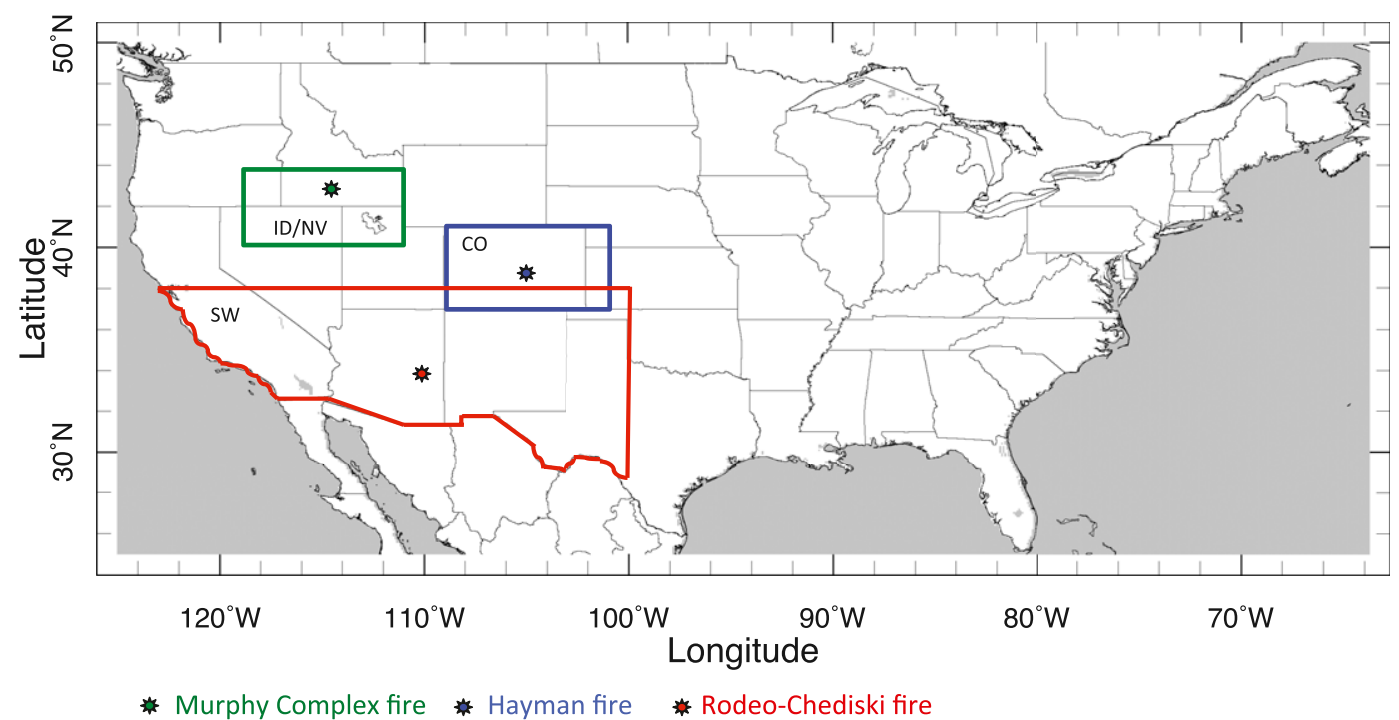

FIG. 1. Map showing the southwest (SW), CO, and ID-NV boxes used in this study as well as the locations of the Rodeo-Chediski and Hayman forest fires and the Murphy Complex rangeland fire.

precipitation offered the best explanation of burned forest area.

Building on the work of Williams et al. (2014, 2015), we examined time histories of annual burned area of forest and grassland versus VPD for the southwestern United States (Fig. 1 shows this and other areas and locations referred to in the paper). The burned areas for 1984-2012 come from the Monitoring Trends in Burn Severity (MTBS) database (Eidenshink et al. 2007) and was extended beyond 2012 by using the MODIS burned area v5.1 dataset (Roy et al. 2008). The burned forest area was found to correlate best with the prior JuneAugust VPD anomaly, while the burned grassland area correlated best with June VPD, reflecting the relative times needed to dry the fuels. These correlations are shown in Fig. 2. VPD is clearly a strong controlling influence on area burned of both vegetation types and an upward trend in both is clearly apparent over past decades (note the logarithmic scale).

VPD is only one fire-related meteorological variable and it is perhaps not always the one with the most explanatory power [e.g., see Winkler et al. (2007) for a discussion of the Haines index, which includes moisture deficit, measured by dewpoint depression, together with atmospheric stability as an index for the development of plume-dominated fires]. However, given the demonstrated importance of VPD to at least one topic of great ecological and social importance, it seems worthwhile to further explore the basic spatial and temporal variations of VPD across North America in terms of seasonal cycle, geographic variation, interannual variability, and long-term trends. To our knowledge, no such study has been conducted. Gaffen and Ross (1999) did conduct a study of climatology and trends of specific and relative humidity across the United States. Their maps of daytime RH show, in

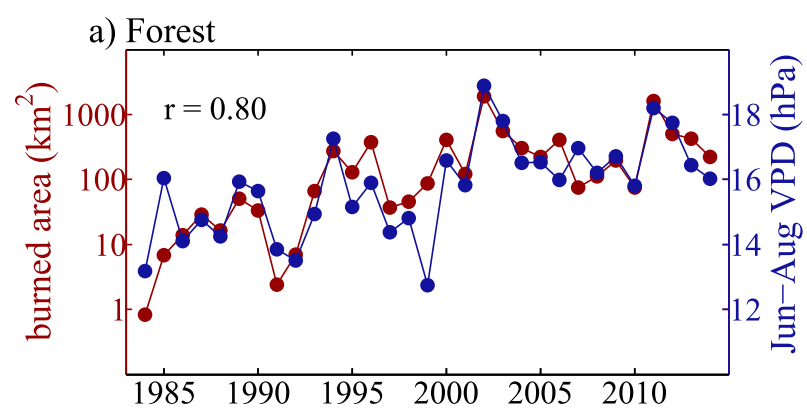

b) Grassland

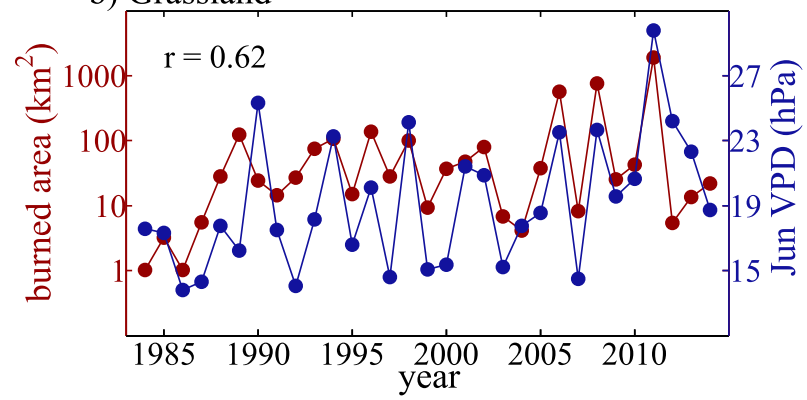

FIG. 2. Time series of annual burned area and VPD for two parts of the southwest United States during 1984-2014. (a) Forest area within parts of AZ, NM, CO, UT, and TX that are south of $38^{\circ} \mathrm{N}$ and west of $104^{\circ} \mathrm{W}$ and prior June-August VPD, (b) grassland area within the parts of NM, TX, and OK that are south of $38^{\circ} \mathrm{N}$ and east of $105^{\circ} \mathrm{W}$ and June VPD. For each region, VPD is shown for the months or month when mean VPD correlated most strongly with annual burned area. 
winter, high values along the West Coast and in the Southeast and low values in the Northeast and, in summer, a striking west-east lower-higher contrast.

To build on Gaffen and Ross (1999), the current study is motivated by the desire to develop a better understanding of the controls on moisture undersaturation in the atmosphere and also the need to improve our understanding of the outbreak and spread of wildland fires. As such, after providing a cross-U.S. analysis of the climatology and variability of VPD, we will examine the atmosphereocean-land causes of VPD variability in the Southwest, as well as the long-term trends in VPD. We will also provide case studies of the VPD anomalies, and their causes, leading up to June 2002 when two major southwest fires (the Rodeo-Chedeski fire in Arizona and Hayman fire in Colorado) occurred and to July 2007 when the Murphy Complex fire occurred in Idaho and Nevada.

\section{Data and methods}

High-quality, spatially and temporally extensive humidity data are hard to come by in general. Here, we use the PRISM dataset developed by the PRISM Climate Group at Oregon State University, details of which can be found online (http://www.prism.oregonstate.edu, last accessed 20 March 2015) and in Daly et al. (2000), and which was obtained from the International Research Institute for Climate and Society website (http://iridl.ldeo. columbia.edu/SOURCES/.OSU/.PRISM/, last accessed 20 March 2015). We analyze the 1961-2012 period. The PRISM dataset provides monthly means of maximum $\left(T_{\max }\right)$ and minimum $\left(T_{\min }\right)$ daily temperature and dewpoint temperature $T_{d}$. We calculated $e_{s}(T)$ and $e_{a}$ from

$e_{s}\left(T_{\max }\right)=e_{\mathrm{s} 0} \exp \left[17.67\left(T_{\max }-T_{0}\right) /\left(T_{\max }-T_{0}+243.5\right)\right]$,

$$
e_{s}\left(T_{\min }\right)=e_{\mathrm{s} 0} \exp \left[17.67\left(T_{\min }-T_{0}\right) /\left(T_{\min }-T_{0}+243.5\right)\right],
$$

and

$$
e_{a}=e_{\mathrm{s} 0} \exp \left[17.67\left(T_{d}-T_{0}\right) /\left(T_{d}-T_{0}+243.5\right)\right],
$$

where $T_{\max }, T_{\min }$, and $T_{d}$ are in kelvins and $T_{0}=$ $273.15 \mathrm{~K}$. Monthly mean $e_{s}$ is then computed as $\left[e_{s}\left(T_{\max }\right)+e_{s}\left(T_{\min }\right)\right] / 2$. The nonlinear dependence of $e_{s}$ on $T$ means that $e_{s}$ computed this way will be different than when computing it using subdaily data. In the appendix, we present an analysis that shows that the error, relative to using 3-hourly data (which are only available for a shorter period), is minimal.

To examine the atmospheric circulation variability associated with VPD variability, we examine geopotential heights and vertical pressure velocities from the National Centers for Environmental Prediction-National Center for Atmospheric Research (NCEP-NCAR) reanalysis (Kalnay et al. 1996; Kistler et al. 2001). The NCEP-NCAR reanalysis was chosen as it is the only reanalysis that assimilates all available information that extends back before 1979 and hence overlaps the PRISM precipitation data. For surface sensible and latent heat fluxes, used to compute the Bowen ratio, we used data from version 2.0 of the Global Land Data Assimilation System (GLDAS), available online (http://disc.sci.gsfc.nasa.gov/gesNews/gldas_ 2_data_release). GLDAS uses a land surface model forced by observed meteorological conditions to estimate the land surface hydrology and surface fluxes of water and energy (Rodell et al. 2004; Sheffield and Wood 2006). All analyses cover the 1961-2012 period and anomalies, when used, are with respect to climatology over this period. The analysis period begins in 1961 because that is when PRISM dewpoint data (used to calculate VPD) are based on true measurements rather than estimated from temperature and precipitation (C. Daly 2014, personal communication).

\section{Climatology of vapor pressure deficit across the United States}

Figure 3 shows the VPD, $e_{s}$, and $e_{a}$ for the four seasons of October-December (OND), January-March (JFM), April-June (AMJ), and July-September (JAS), which correspond to the hydrological year and which we shall refer to as fall, winter, spring, and summer, respectively. The VPD is lowest in the winter season; that is, the air is closest to saturation at this time. This is partially caused by the low $e_{s}$, following on the coldest temperatures of the year, which places an upper bound on how large VPD can be. A vast area of western North America and north-central and eastern North America has $e_{s}$ below $8 \mathrm{mb}(1 \mathrm{mb} \equiv 1 \mathrm{hPa})$ in the winter. The VPD pattern is largely zonal in winter because the warmer West Coast areas with higher $e_{s}$ are also areas of higher $e_{a}$. The coastal eastern regions have less of a maritime climate and a more continental climate because of the prevailing westerlies, and VPD, $e_{s}$, and $e_{a}$ here are continuous with the interior United States to the west.

By spring the VPD has climbed above $8 \mathrm{mb}$ across the majority of the United States except for most of the northern states. What is striking is the area of around 30-mb VPD in the interior southwest United States. This is driven by a sharp rise in $e_{s}$. However, $e_{s}$ rises by almost as much across the south-central and southeastern United States, but in these regions this does not translate into a similar rise in VPD because $e_{a}$ also rises while it does not in the 
OND
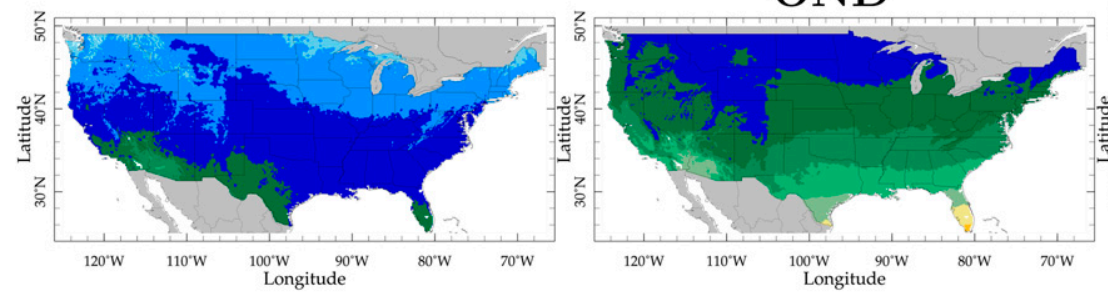

JFM
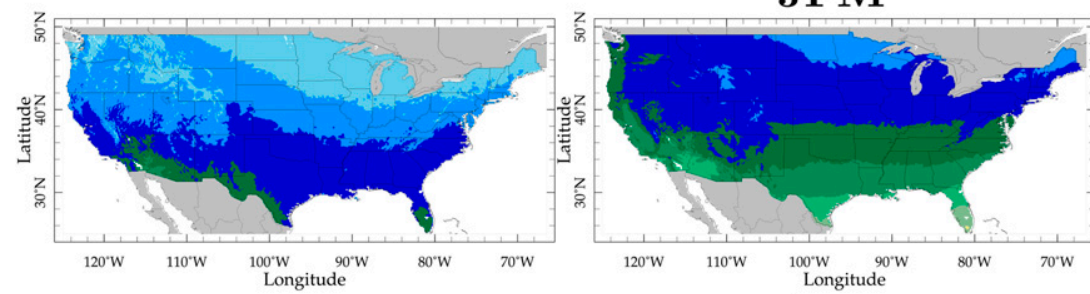

AMJ
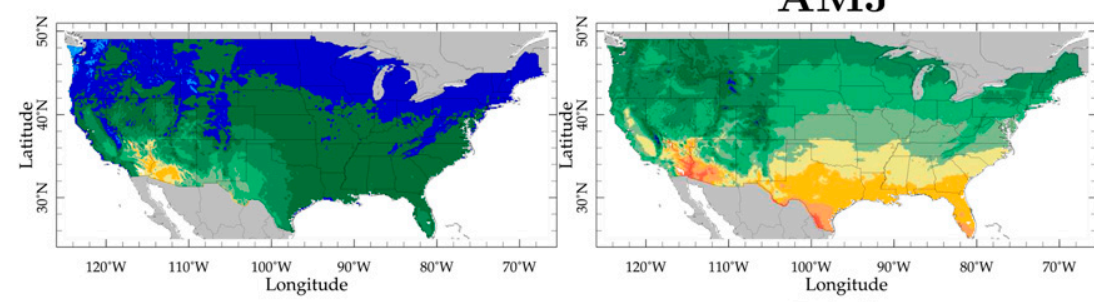

JAS
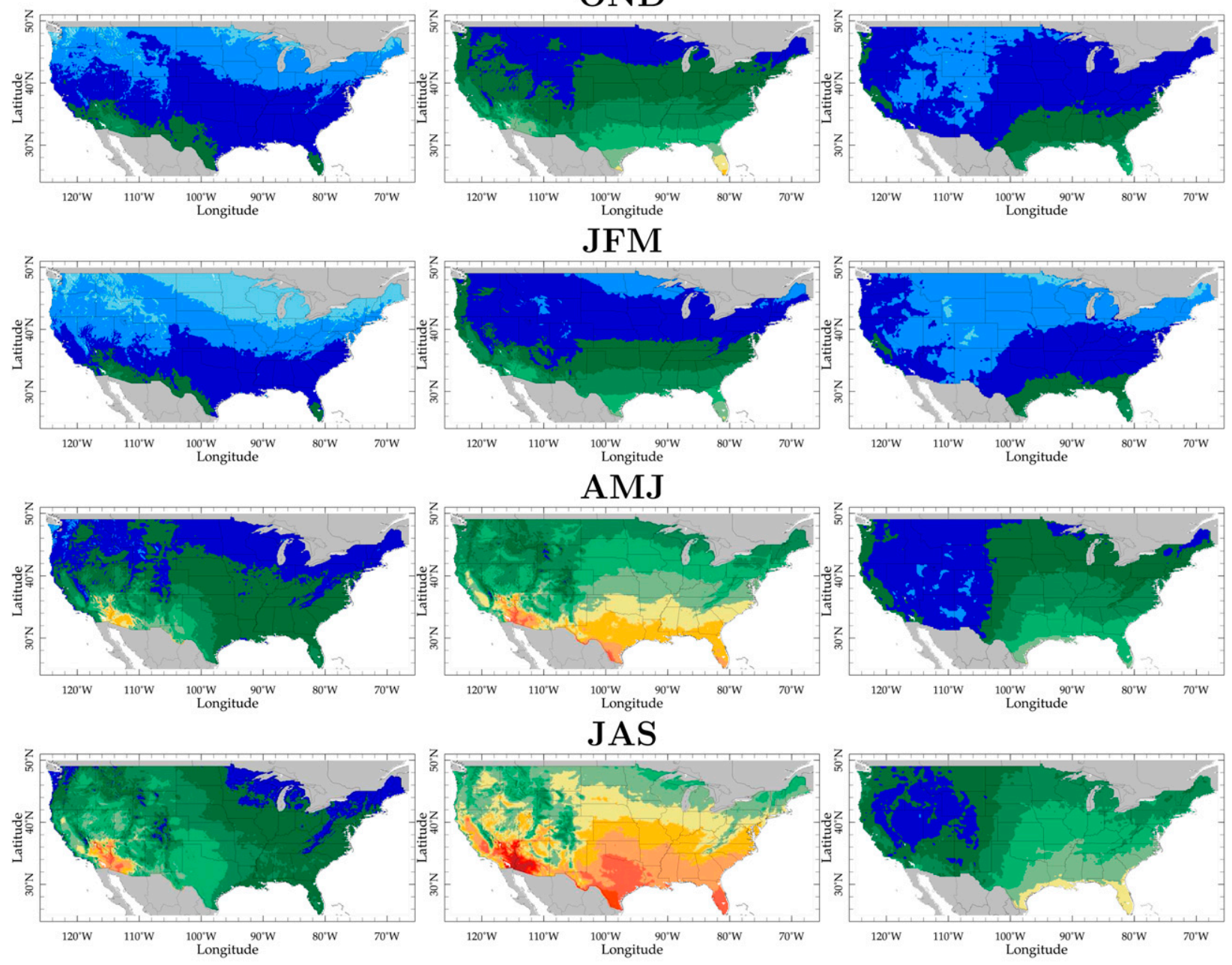

FIG. 3. The climatology of (left) VPD, (center) $e_{s}$, and (right) $e_{a}$ for the fall, winter, spring, and summer seasons.

interior southwest region. These differences are, in turn, related to the development of the Atlantic subtropical high and moisture convergence in southerly flow over the southern United States (e.g., Seager et al. 2003b), whereas moisture flow into the interior southwest awaits the arrival of the North American monsoon (Adams and Comrie 1997). The switch from winter with more frequent northerly flow to spring with more frequent southerly flow, associated with the development of the Atlantic subtropical high, is evident in the rise of $e_{a}$ across the United States from the plains to the Atlantic coast.

In going from spring to summer, VPD increases modestly over the eastern United States, especially in the northern region but climbs strongly in the southwest and across the west. The highest monthly mean values that ever occur in the United States (above $40 \mathrm{mb}$ ) are found in summer in southeastern California, southern Nevada, and southwestern Arizona. This is related to high temperatures driving high $e_{s}$ and outstripping the increase in $e_{a}$. High $e_{a}$ across the remainder of the southern United States and the Southeast balances high $e_{s}$ and keeps VPD relatively low. The northwestern, north-central, and northeastern regions of the United States have their maximum VPD values in summer, as $e_{a}$ fails to keep up with the highest values of $e_{s}$ driven by the warmest temperatures of the year. In fall all quantities are well on their way, after summer, to reestablishing their winter states. 
OND
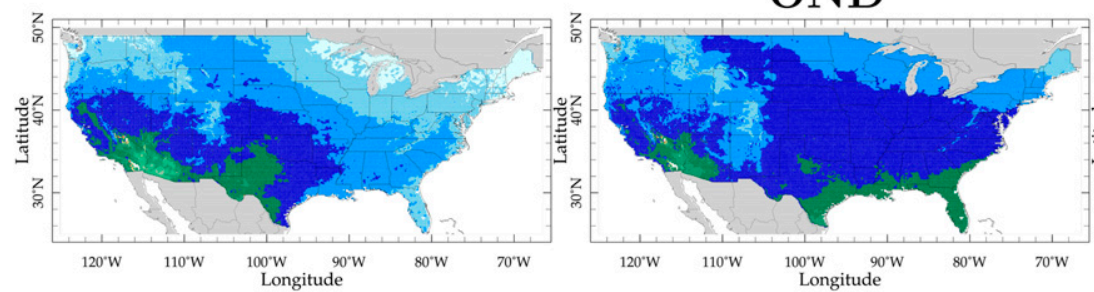

JFM
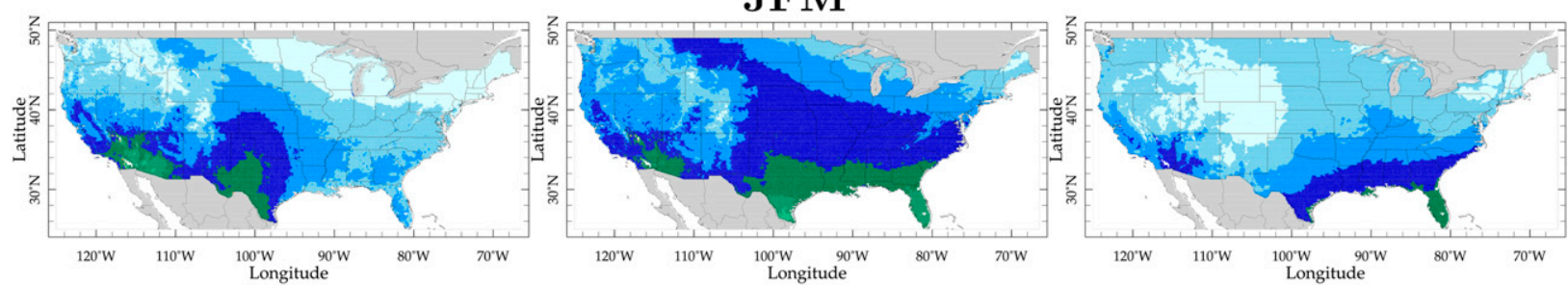

AMJ
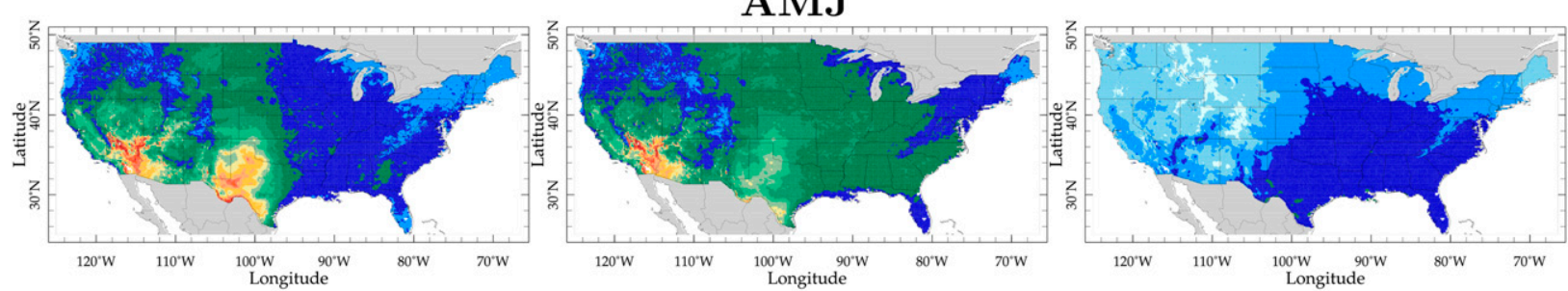

JAS
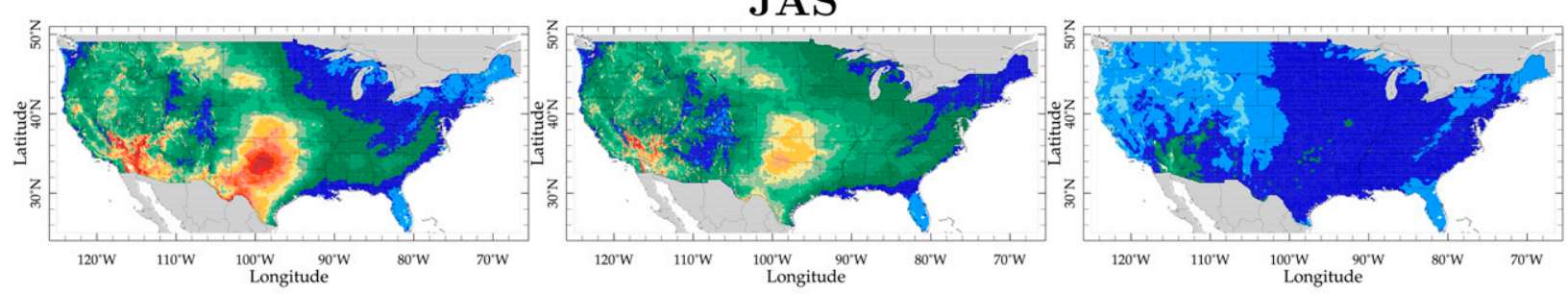

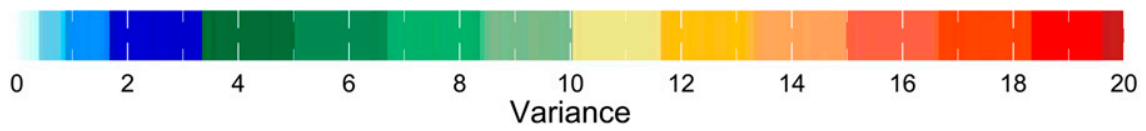

FIG. 4. As in Fig. 3, but for variances $\left(\mathrm{mb}^{2}\right)$.

\section{Interannual variability of VPD across the United States}

While the climatology of VPD is interesting, ecosystems are presumably largely evolved to deal with this. They will also be able to adapt, to some extent, to year-toyear variability. However, extreme high VPD years are expected to exert considerable water stress on vegation, leading to a risk of disease, fire, and mortality (Williams et al. 2013; Sedano and Randerson 2014). Hence, we next turn to examine the variability of VPD and its causes throughout the post-1961 period. To do this, we computed the variance of VPD, $e_{s}$, and $e_{a}$ for each month and then averaged these monthly variances to form seasonal mean variances, which are shown in Fig. 4.
In no season is the VPD variance simply proportional to the VPD climatology. In the fall and winter the VPD variance has a southwest-maximum-northeast-minimum pattern with lines of equal variance oriented in a roughly northwest-to-southeast manner. This is in contrast to the more zonal pattern of the VPD climatology. This VPD variance pattern is quite distinct from that of the $e_{s}$ and $e_{a}$ variances, which are maximum over the southeastern United States. Since these do not translate into a VPD variance maximum, it must be because they vary together; that is, $e_{s}^{\prime} \approx e_{a}^{\prime},\left(e_{s}-e_{a}\right)^{\prime} \approx 0$. One reason for this is that in these seasons transient eddies dominate the moisture convergence into the southeastern and eastern United States (Seager et al. 2014b). The eddies act to diffuse temperature and moisture such that, in southerly flow, they 
will both warm, increasing $e_{s}$, and moisten, increasing $e_{a}$, and vice versa for northerly flow, minimizing the change in VPD. In contrast, in the Southwest the $e_{s}$ variance is also large but not compensated for by similarly large $e_{a}$ variance. These comparisons make clear that, in general, the VPD variance cannot be explained as being purely temperature driven with, for example, $e_{s}$ varying and the VPD variations simply related to this according to fixed $\mathrm{RH}$.

In the spring, the Southwest region of climatological high VPD is also a region of high VPD variance and this is driven by high $e_{s}$ variance (i.e., by temperature variance), while the $e_{a}$ variance is quite low. There is also a central U.S. maximum of VPD variance that stretches from Texas to the northern plains, which arises from a maximum of $e_{s}$ (i.e., temperature) variance. In the summer many of the features of the VPD and $e_{s}$ variances seen in spring remain but are amplified. Maximum VPD variance occurs in the Mojave, Sonora, and Chihuahua Desert portions of the southwest United States. These are all regions of high $e_{s}$ variance. In summer a modest $e_{a}$ variance maximum develops in southeast California and southwest Arizona, which is likely due to the variance of moisture convergence in the North American monsoon.

The regions of low spring and summer $e_{s}$ variance in the interior West, which translate into lower VPD variance, are related to high topography where the climatological $e_{s}$ and $e_{a}$ values are lower than in lowerlying surrounding areas. This can be understood as follows. The $e_{s}$ variance, $\sigma_{e_{s}}^{2}$, for a given month is given by

$$
\sigma_{e_{s}}^{2}=\frac{1}{N} \sum_{n=1}^{N} e_{s, n}^{2},
$$

where $n$ indicates the year, $N$ is the total number of years, and the prime indicates departure from the monthly mean climatology. We can linearize $e_{s}^{\prime}$ as

$$
\left.e_{s}^{\prime} \approx \frac{d e_{s}}{d T}\right|_{T_{a}} T_{a}^{\prime},
$$

that is, the gradient of $e_{s}$ with respect to $T$ evaluated at the climatological mean air temperature, $\overline{T_{a}}$, multiplied by the air temperature anomaly $T^{\prime}$. Substituting Eq. (9) into Eq. (8), we get

$$
\sigma_{e_{s}}^{2}=\frac{1}{N} \sum_{n=1}^{N}\left(\left.\frac{d e_{s}}{d T}\right|_{T_{a}} T_{a}^{\prime}\right)^{2} .
$$

Since $d e_{s} / d T$ increases with $T$, the same temperature variance will give lower $e_{s}$ variance at lower climatological mean temperatures. When $e_{s}$ variance is estimated with Eq. (10) (not shown), it is clear that this effect, in combination with lower temperature variance at colder temperatures, explains the low $e_{s}$ and VPD variance at higher elevations in western North America.

The clear and expected increase in the variance of vapor pressure quantities with the mean values suggests that normalized standard deviation may be a more informative measure. Hence, Fig. 5 shows the standard deviations normalized by their climatological values and expressed as a fraction. In this case large values show that the variance (the square of the standard deviation) is unusually large in comparison to the climatological value while small values show the opposite. The Southwest desert maximum of VPD variance does not appear on the maps of normalized standard deviation. Instead, the normalized standard deviation of VPD emphasizes the north-central United States in fall and winter and the plains and west other than the interior southwest in spring and summer. Hence, some areas of relatively low absolute VPD variance in the Pacific Northwest states appear as high areas of relative variability. In this regard, it is worth noting that Stavros et al. (2014) show that several measures of fire activity are greater in the northern parts of the western United States than the southern parts. The normalized standard deviations of $e_{a}$ are also different than those of the absolute variance of $e_{a}$. While the latter track the climatological $e_{a}$, the former shows the Southwest areas of high VPD variances to be ones of relatively high $e_{a}$ variability. Looked at in this way, it appears that high VPD variance in regions of the Southwest does not just arise from high temperature, $e_{s}$, and $e_{s}$ variance but also from the relatively high variability of $e_{a}$. This is suggestive of a potential role for the driving of atmospheric humidity variability by locally strong atmospheric circulation variability, that is, a role for atmospheric dynamics as well as thermodynamics.

\section{Relationship of VPD variability in the southwest United States to SST and circulation variability}

The analysis above has shown that VPD variability is largest in the southwest United States at the California-Arizona border. However, this is a very arid region, with high climatological VPD, and not one with extensive fire occurrence as a result of the absence of extensive vegetation. Fire occurrence is more common in regions of lower climatological VPD that are less arid and can sustain vegetation that is nonetheless susceptible to burning. We have already shown that VPD variability is large in these intermediate aridity regions in the spring and summer seasons critical for fires and that this is influenced strongly by $e_{s}$ variability but also by $e_{a}$ variability. But what controls VPD, $e_{s}$, and $e_{a}$ variability? 
OND
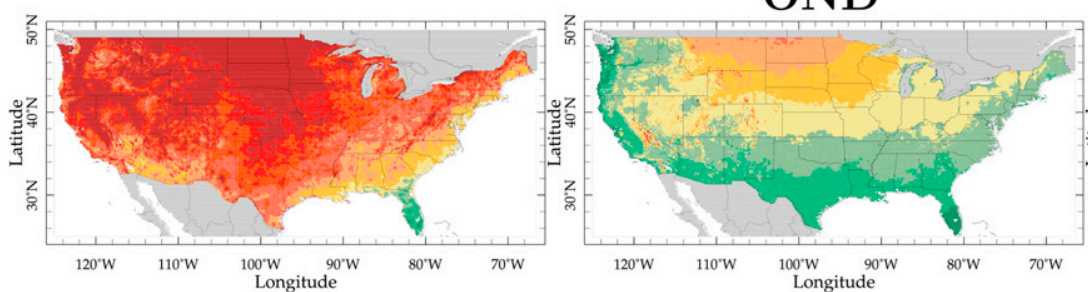

JFM
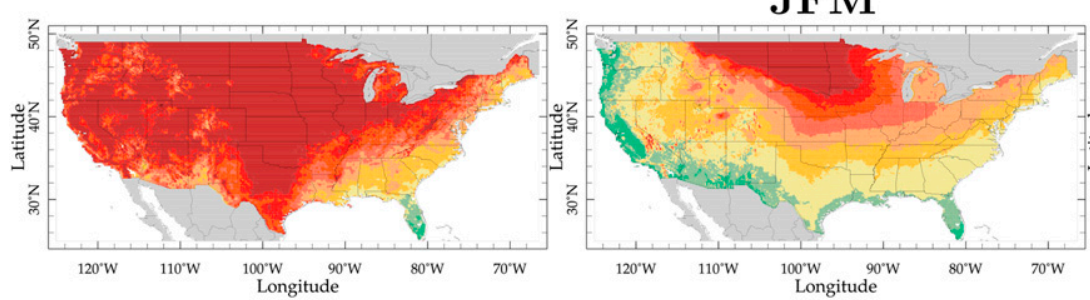

AMJ
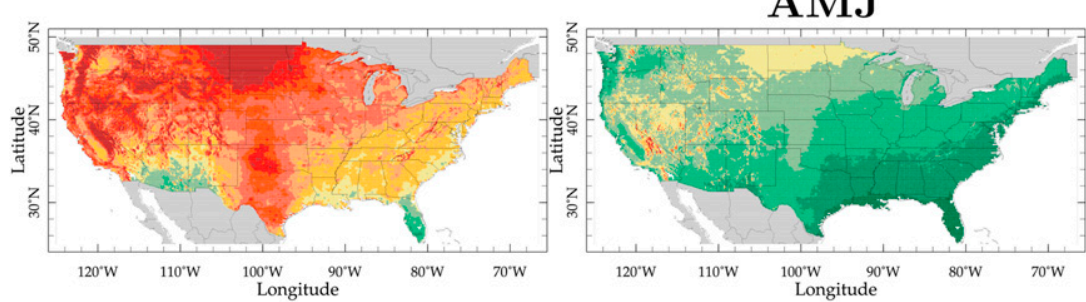

JAS
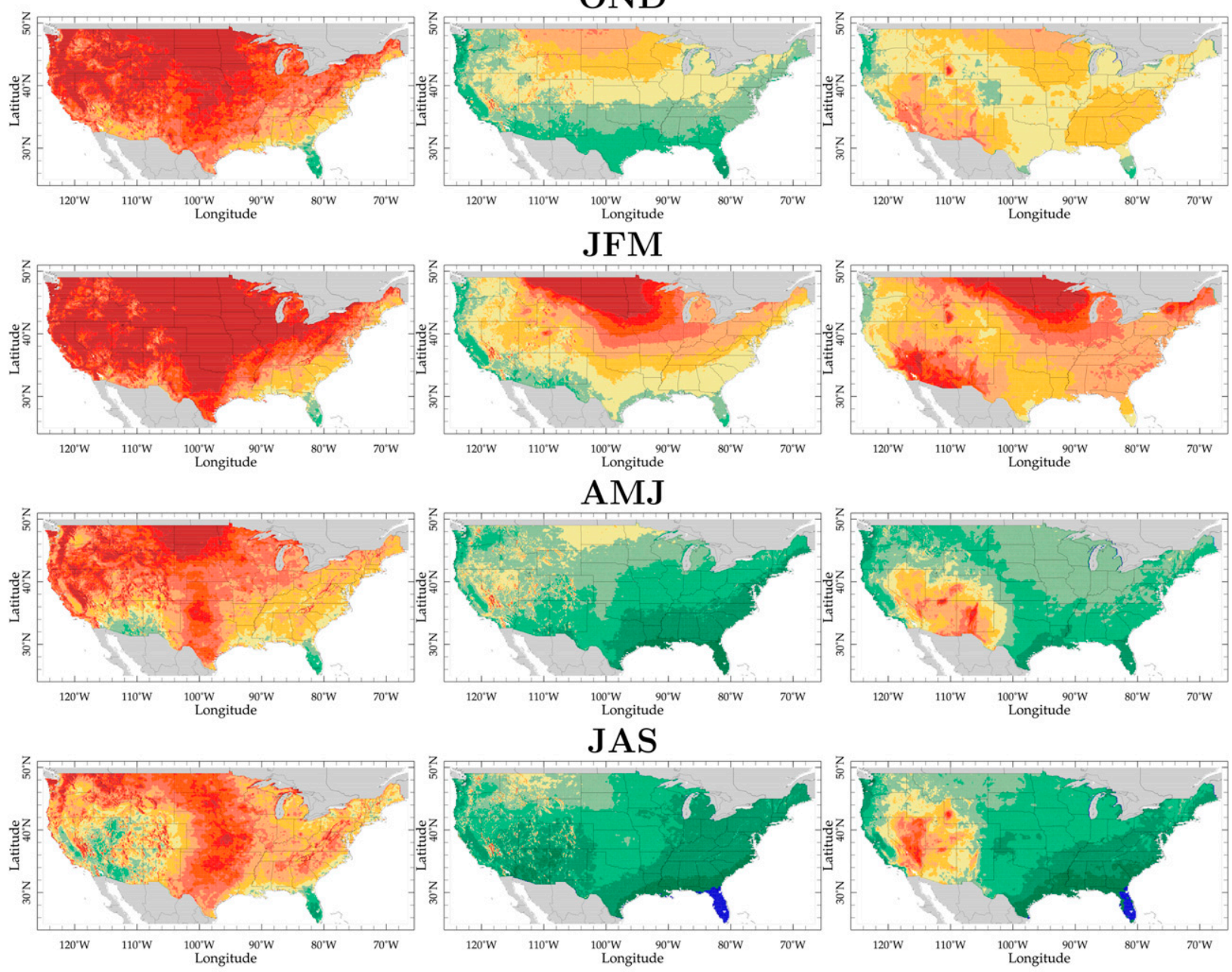

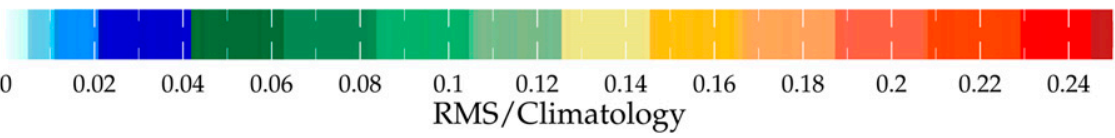

FIG. 5. As in Fig. 4, but for the standard deviation divided by the climatological values.

To look at this, we examine the correlation between $\mathrm{VPD}, e_{s}$, and $e_{a}$, as well as atmospheric circulation, as measured by the 700-mb geopotential height, and sea surface temperature (SST) variability. We focus in on the region of high fire occurrence identified by Williams et al. $(2014,2015)$. This Southwest area lies to the east of the region of very high VPD climatology and variance at the California-Arizona border and includes the parts of Arizona, New Mexico, Texas, Oklahoma, Colorado, and Utah bounded by $28^{\circ} 5$ and $38^{\circ} \mathrm{N}$ and to the west of $100^{\circ} \mathrm{W}$. The $700-\mathrm{mb}$ level is chosen since it does not intersect with topography but is close to the level in the atmosphere where significant moisture transport occurs. Results are shown in Fig. 6. In fall, winter, and spring high VPD in the Southwest correlates with local high pressure. In fall this is part of a zonal wave pattern and in winter and spring it is part of a general midlatitude ridge that extends across the Pacific, North America, and the Atlantic. High VPD is also correlated with cool tropical Pacific SSTs in winter and spring and, to a lesser extent, in fall. The circulation patterns are what is expected given the La Niña SST pattern (Seager et al. 2003a, 2005, 2014a). These relations make clear that high VPD in the Southwest is promoted by La Niña conditions. This relation breaks down in the summer, which is expected given the general weakness of tropicalmidlatitude teleconnections during this season (Kumar and Hoerling 1998).

High $e_{s}$ is also correlated with high geopotential heights and La Niña SST conditions, and the patterns of each are 


\section{OND}
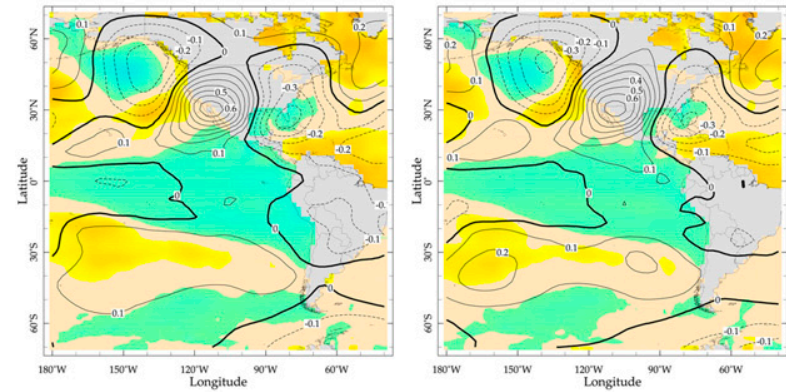

JFM
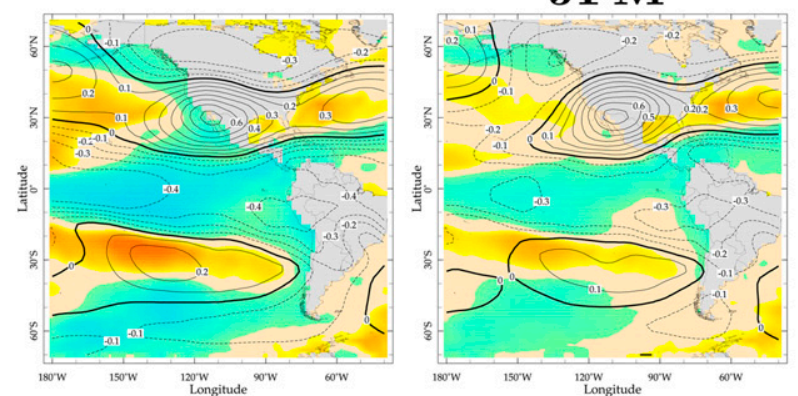

AMJ
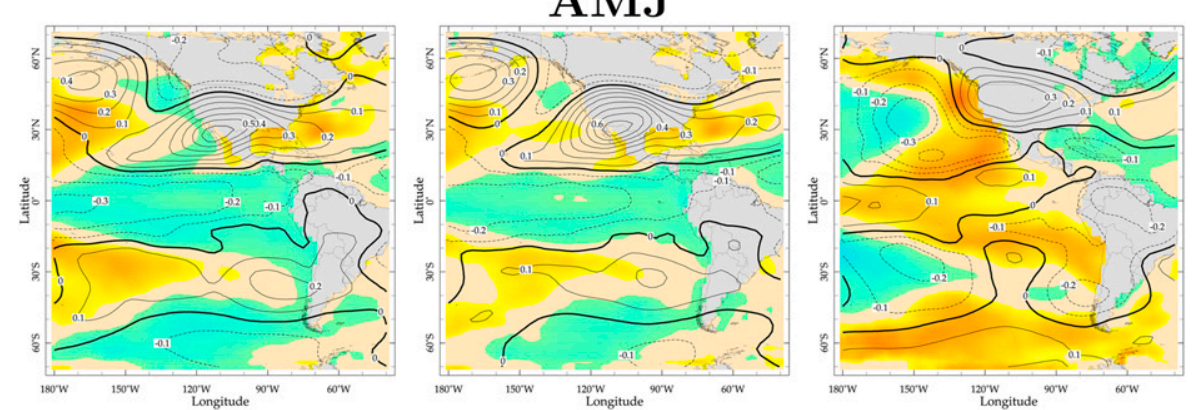

JAS
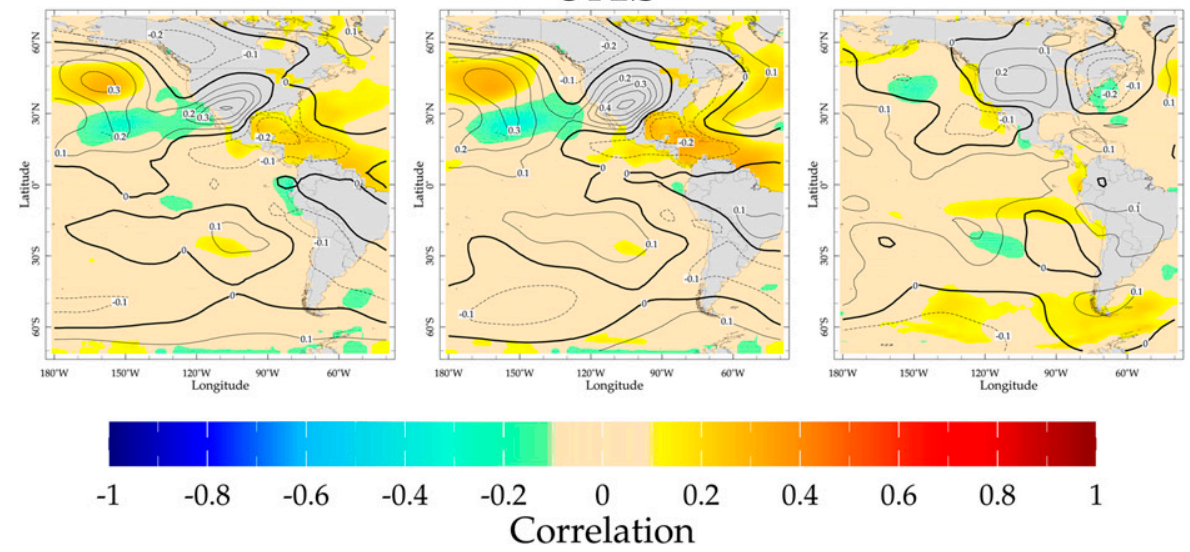

FIG. 6. The detrended correlations between (left) VPD, (center) $e_{s}$, and (right) $e_{a}$ in the U.S. southwest and 700-mb geopotential heights (contours) and SST anomalies (colors) by season.

quite similar to those for the VPD correlations. This indicates that high VPD anomalies are being driven, in large part, by an increase in temperature causing high $e_{s}$. The correlations with $e_{a}$ in fall and winter are such that low $e_{a}$, which would contribute to high VPD, also arises from La Niña conditions. The La Niña connection to low $e_{a}$ is also clear in the spring, though the associated height anomaly pattern is different from those for the VPD and 
$e_{s}$ correlations. The summer $e_{a}$ correlation, as expected, does not have a feature in the tropical Pacific and the circulation anomaly indicates high $e_{a}$ corresponding to low pressure off Baja California and high pressure over the Rocky Mountains.

These relations are fairly easy to explain. During La Niña conditions in the fall, winter, and spring, high pressure develops and is centered over northwestern Mexico, which favors subsidence over the southwest United States, causing both high temperatures and high $e_{s}$, via warming due to compression and low $e_{a}$ due to the subsidence of dry air. Both effects drive the VPD to be high. In summer, when the connection to the tropical oceans is weak, high VPD and $e_{s}$ in the Southwest are still favored by local high pressure (and, presumably, subsidence warming) while low $e_{a}$ appears to be favored by flow anomalies from the north and west, which makes sense since the moisture sources for the Southwest lie to the south over the Gulfs of California and Mexico. We also examined relations of VPD, $e_{s}$, and $e_{a}$ that lagged behind SST and heights 3 months prior and these are similar to those shown here but much weaker, with the persistence presumably provided by the SST anomalies.

\section{Relationship of variability of VPD to land surface conditions}

While atmospheric circulation anomalies are expected to be able to influence VPD instantaneously via subsidence of warm, dry air, it is also expected that previous reductions in precipitation could dry out the soil and lead to an increase in VPD. As the soil dries out, incoming solar radiation needs to be increasingly balanced by sensible and longwave radiative heat loss, and less by evapotranspiration. This requires an increase in surface temperature and less moisture flux from the surface to the atmosphere, both effects that increase VPD. One measure of soil dryness is the Bowen ratio, $B=\mathrm{SH} / \mathrm{LH}$, where $\mathrm{SH}$ is surface sensible heat flux and LH is surface latent heat flux.

The previous section showed that VPD increases as atmospheric circulation anomalies cause warming and/ or drying. In the absence of a surface moisture anomaly, subsidence warming and drying would be expected to increase $\mathrm{LH}$ and reduce $\mathrm{SH}$, surface flux changes that would offset the circulation-induced changes in VPD. This would cause a reduction in the Bowen ratio to accompany the increase in VPD.

Figure 7 shows the correlation across the United States between seasonal VPD and the Bowen ratio. In the western United States (except for the Pacific Northwest in spring), the Bowen ratio increases with
VPD throughout the year. There are also positive correlations across the central and eastern United States in summer and fall. Areas of negative correlation develop in the south-central United States in winter and most of the eastern United States in spring. The strongest positive correlations are in the interior West and along the Gulf Coast in summer.

The cause of these correlations can be understood in terms of the correlation of Bowen ratio with $e_{s}$ and $e_{a}$, which is also shown in Fig. 7. The correlation between Bowen ratio and $e_{a}$ is simple and essentially always negative. That is, as the latent heat flux goes up, and the Bowen ratio drops, the atmospheric water vapor rises. This suggests that the atmospheric vapor pressure is responding to changes in evapotranspiration. The relation of Bowen ratio with $e_{s}$ is more spatially variable. In the central and southern parts of the West, the Bowen ratio tends to rise as temperature rises while in the central to eastern United States and in the northwest the Bowen ratio tends to decrease as temperature rises. The exception is summer when, apart from some northern states, the Bowen ration tends to rise as $e_{s}$ rises.

The winter negative Bowen ratio- $e_{s}$ correlation in the central and eastern United States can be understood in terms of atmospheric driving. During these seasons of high surface moisture availability, a warm anomaly (of whatever origin) will cause an increase in $e_{s}$, an increase in latent heat flux, a drop in the Bowen ratio, and an increase in $e_{a}$. The general east-west correlation contrast probably reflects the east-west high-low precipitation-dryness contrast. That is, the eastern half receives considerable precipitation in summer and generally has ample surface moisture supply while the west receives little summer precipitation and the surface is drier. As such, warm temperature anomalies can drive higher latent heat flux and a lower Bowen ratio in the eastern half of the country. In contrast, across the West throughout the year, moisture is in shorter supply and drying (due, e.g., to a precipitation reduction) can cause a reduction in latent heat flux and both an increase in the Bowen ratio and warming as the sensible and longwave heat flux rise to balance the incoming solar radiation. The Bowen ratio-temperature and $e_{s}$ correlations are, therefore, driven by the atmosphere in the East and by the land surface in the West. The exception is that during summer, as soils dry out because of high atmospheric evaporative demand, the positive Bowen ratio- $e_{s}$ correlation occurs essentially across the United States.

The correlation between VPD and Bowen ratio combines the influences of the correlations of Bowen ratio with $e_{s}$ and $e_{a}$. Across the West, in winter, an increase in 
OND
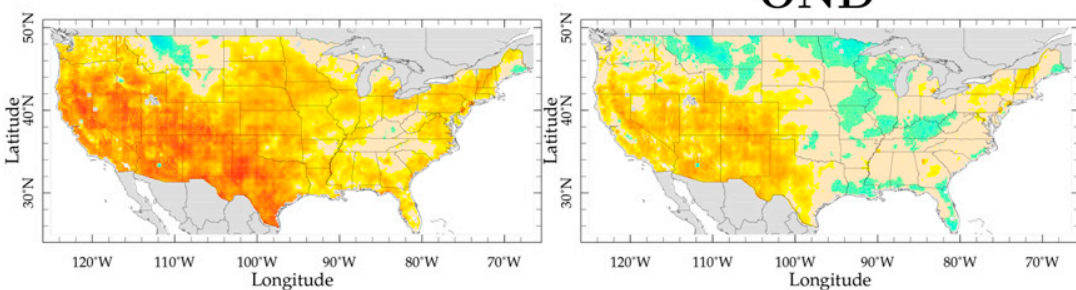

JFM
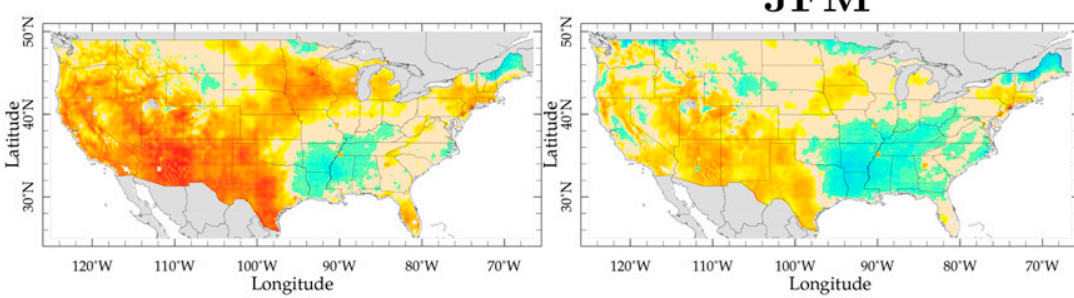

AMJ
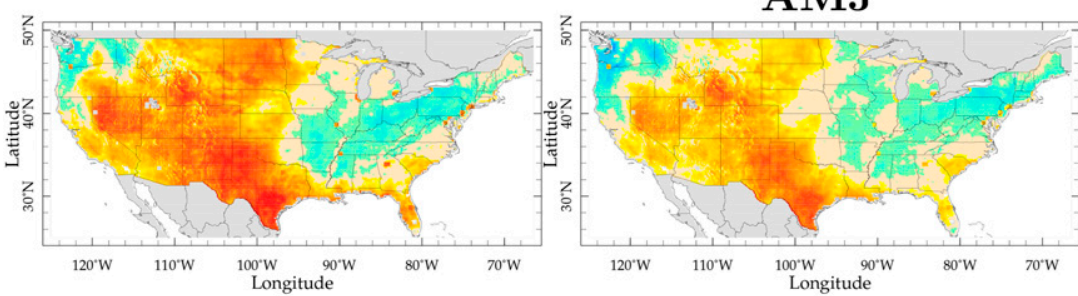

JAS
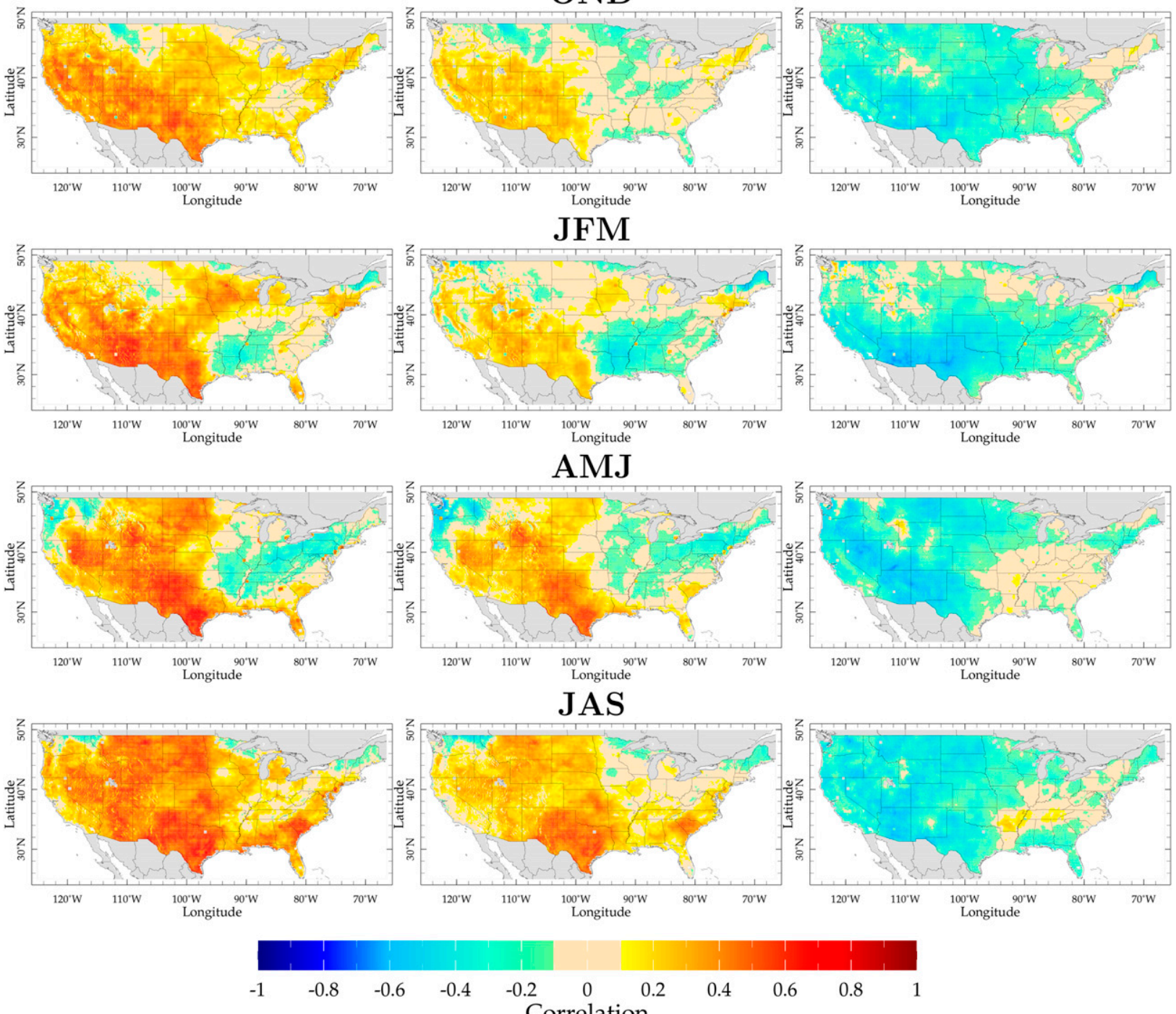

Correlation

FIG. 7. As in Fig. 6, but for correlations between Bowen ratio and (left) VPD, (center) $e_{s}$, and (right) $e_{a}$.

latent heat flux drives a drop in Bowen ratio, an increase in $e_{a}$, and a drop in VPD. Farther east in winter the Bowen ratio and VPD are less correlated while in spring there are widespread areas of negative correlation around the Ohio River valley. This can be explained if a warm anomaly increases latent heat flux and decreases the Bowen ratio and at the same time causes $e_{s}$ to rise by more than $e_{a}$ thus increasing the VPD. In the summer, by contrast, VPD and the Bowen ratio are positively correlated essentially everywhere and most strongly in the dry West. Across the United States a decrease in surface moisture (say, due to a decrease in precipitation) causes a decrease in latent heat flux and an increase in Bowen ratio but also an increase in surface temperature and $e_{s}$ (as less of the incoming solar radiation is balanced by latent heat flux) and a decrease in $e_{a}$ and, hence, an increase in VPD.

Hence, it might be expected that VPD will rise following a period of reduced precipitation that dries the surface. We also computed the correlations with VPD, $e_{s}$, and $e_{a}$ lagged 3 months behind the Bowen ratio but, in this case, the correlations were very low. This suggests that the memory land surface conditions impart to following season atmospheric moisture properties is short. Since the changes in atmospheric circulation that cause warming and/or drying of surface air will nearly instantaneously cause an increase in VPD, the land surface and atmospheric circulation mechanisms of altering VPD show no clear sign of long-term predictability other than that imparted by the influence of SST on circulation. 


\section{Relation of Southwest, Colorado, and Idaho- Nevada region VPD to the combined effects of land surface and atmospheric conditions}

To illustrate the effects of land surface and atmospheric conditions, we conducted a multiple linear regression of VPD, Bowen ratio, and 700-mb geopotential height all averaged over the Southwest box, a Colorado box $\left(37^{\circ}-\right.$ $\left.41^{\circ} \mathrm{N}, 109^{\circ}-101^{\circ} \mathrm{W}\right)$, and an Idaho-Nevada box $\left(40^{\circ}-44^{\circ}\right.$, $\left.119^{\circ}-112^{\circ} \mathrm{W}\right)$. The Colorado region was chosen as it encompasses the area of the 2002 Hayman fire discussed below. The southern Idaho-northern Nevada region was chosen as it encompassed the Murphy Complex fire in July 2007, also discussed below. First, we used linear regression to determine the relation between VPD and Bowen ratio $B$ as follows:

$$
\operatorname{VPD}(t)=\mathrm{VPD}_{B}(t)+\epsilon(t)=a B(t)+c+\epsilon(t),
$$

where $\operatorname{VPD}_{B}(t)$ is the VPD reconstructed on the basis of $B$ alone and $\epsilon$ is the unexplained residual. We then performed a multiple regression between VPD, $B$, and the 700-mb geopotential height $H$ as follows:

$$
\operatorname{VPD}(t)=\operatorname{VPD}_{B H}(t)+\hat{\epsilon}(t)=\hat{a} B(t)+\hat{b} H(t)+\hat{c}+\hat{\epsilon}(t),
$$

where $\operatorname{VPD}_{B H}(t)$ is the VPD reconstructed on the basis of $B$ and $H$; the values of $\hat{a}$ and $a, \hat{b}$ and $b$, and $\hat{c}$ and $c$ need not be the same; and $\hat{\epsilon}$ is the residual unexplained by the multiple regression. The time series of AMJ and JAS seasonal means of $\mathrm{VPD}_{B}, \mathrm{VPD}_{B H}$, and the actual VPD are shown in Fig. 8 for the Southwest, Colorado, and Idaho-Nevada area averages. In the cases of the Southwest and Colorado during AMJ, the reconstructions of VPD based on the Bowen ratio alone are not very accurate but the reconstructions based on the Bowen ratio (the land surface influence that builds in prior precipitation) and geopotential height (the contemporary atmospheric circulation influence) are reasonably accurate. In contrast, for the Idaho-Nevada region, the AMJ variance is almost entirely explained by geopotential height. During JAS for the Southwest and Colorado regions there is a high degree of correspondence between the VPD, VPD ${ }_{B}$, and $\mathrm{VPD}_{B H}$ time series indicating that there is a high degree of constructive land surface and atmospheric circulation influence on VPD. For the Idaho-Nevada region, in contrast to the spring situation, the VPD variance is about equally explained by the Bowen ratio and geopotential height. The Bowen ratio and geopotential height together explain $69 \%, 60 \%$, and $71 \%$ of the variance of AMJ seasonal means of VPD, and $67 \%, 55 \%$, and $61 \%$ of the variance of JAS means of VPD in the Southwest, Colorado, and Idaho-Nevada regions, respectively. We are not proposing that such a simple regression model be used as a potential means for predicting VPD in early fire season, but simply wish to better illustrate the land surface and atmosphere controls on VPD. It is quite likely that a more extensive search for predictor variables will lead to better relations than have been shown here.

\section{Trends in VPD across the United States}

Next we consider whether there are long-term trends in VPD and its contributors. Trends are evaluated via a straightforward least squares regression of seasonal mean VPD, $e_{s}$, and $e_{a}$ for the 1961-2012 period and results are shown in Fig. 9. These reflect warming trends. There are some weaker trends to lower $e_{s}$ in the north and central United States in spring. The value of $e_{a}$ has been rising in the southeast in fall, in the south-central United States in winter, across the whole eastern United States in spring and the whole eastern United States plus the northern plains in summer. However, $e_{a}$ has actually been falling in the Southwest in summer, as noted before by Isaac and van Wijngaarden (2012) using station data from 1948 to 2010 . As a consequence of the rise in $e_{s}$ and drop in $e_{a}$, there has been a strong trend toward increased VPD in the Southwest in spring and summer. Elsewhere in the West in summer, VPD has also increased as a result of the rise in $e_{s}$. In the northern plains (and to a lesser extent across the northern United States), VPD has actually decreased as $e_{a}$ has risen but $e_{s}$ (and hence temperature) has stayed steady. These trends toward higher VPD in the West are consistent with identified trends in wildfires (Dennison et al. 2014).

\section{Changes in VPD up to and during the June 2002 Hayman and Rodeo-Chediski and July 2007 Murphy Complex fires}

A main motivation of this paper is exploring the importance of VPD to the occurrence of fires in the western United States. Two important fires of the past decade are the Rodeo-Chediski fire in Arizona and the Hayman fire in Colorado, both of which began in June 2002 , in the heart of a major multiyear western drought (Seager 2007; Weiss et al. 2009; Cayan et al. 2010). The Rodeo-Chediski fire burned from 18 June to 7 July 2002 and burned 189095 ha of ponderosa pine and mixed conifers in northern Arizona, worse than any previous recorded Arizona fire (Schoennagel et al. 
AMJ
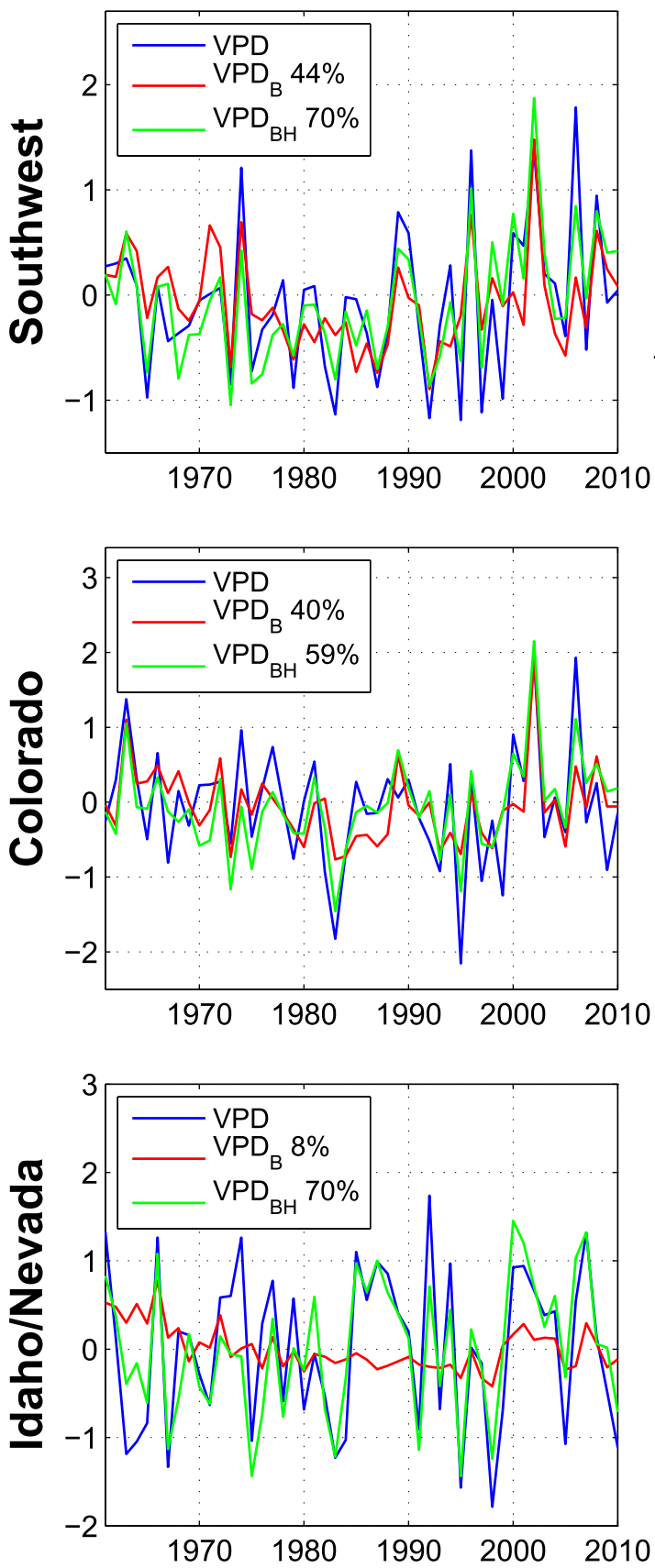

JAS
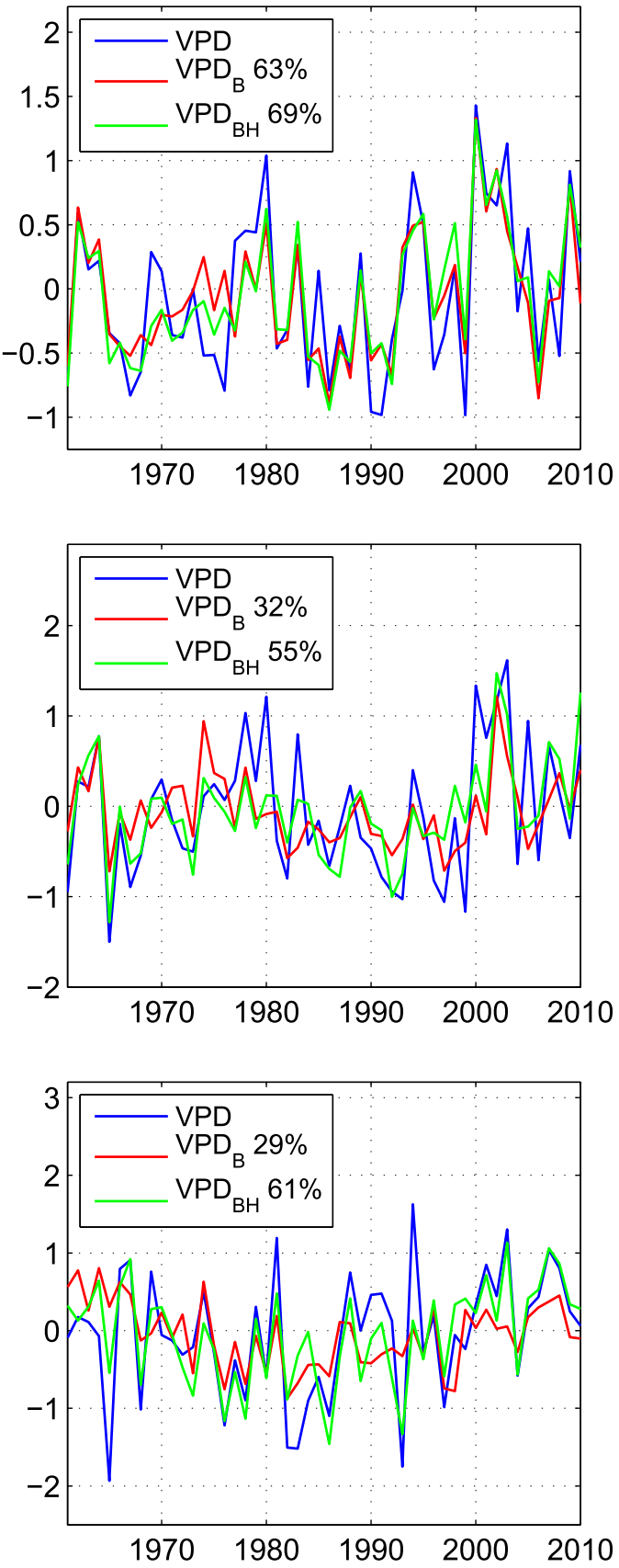

FIG. 8. The actual VPD for (left) AMJ and (right) JAS and its reconstruction via linear regression based on Bowen ratio alone $\left(V_{B}\right)$ and both Bowen ratio and 700-mb geopotential height $\left(V_{B H}\right)$, all normalized, for the (top) Southwest, (middle) CO, and (bottom) ID-NV regions. The percent variance explained by the regressions is marked.

2004). The Hayman fire was smaller and burned 55915 ha to the southwest of Denver beginning on 9 June 2002 (Schoennagel et al. 2004) and remains the worst fire in recorded Colorado history. Further, based on dendroecological records Williams et al. (2013) found 2002 to be the most severe year for forest drought stress in the Southwest since at least the year 1000. These facts motivate the presentation here of meteorological conditions and VPD anomalies in the months preceding the June 2002 fires. We also examine 
OND
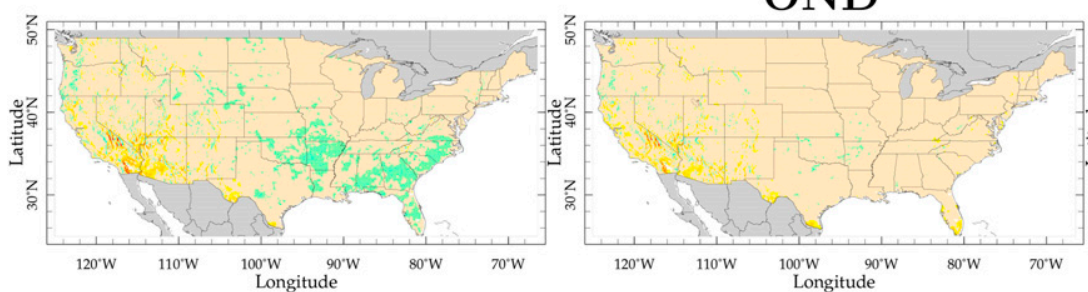

JFM
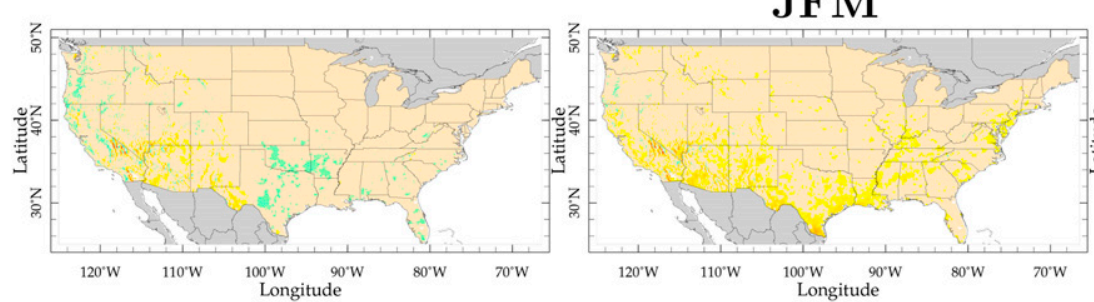

AMJ
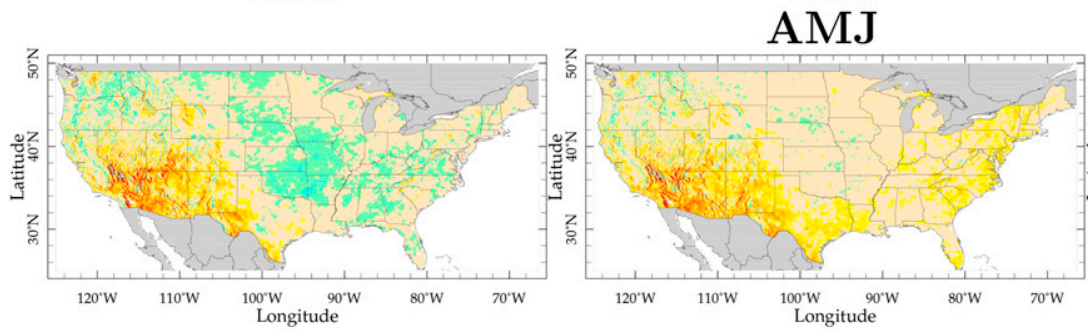

JAS
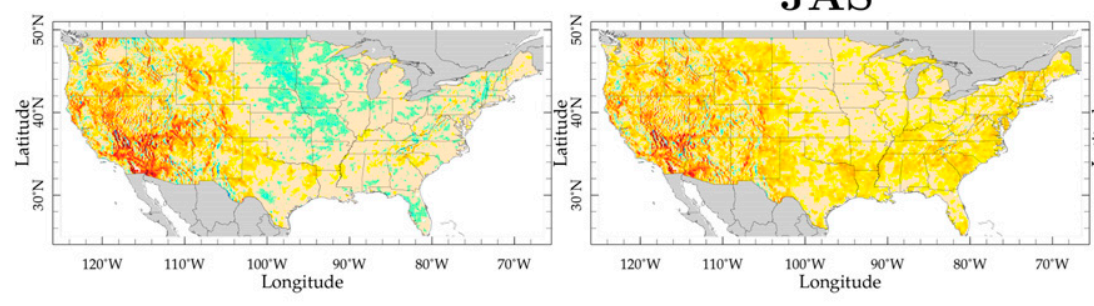
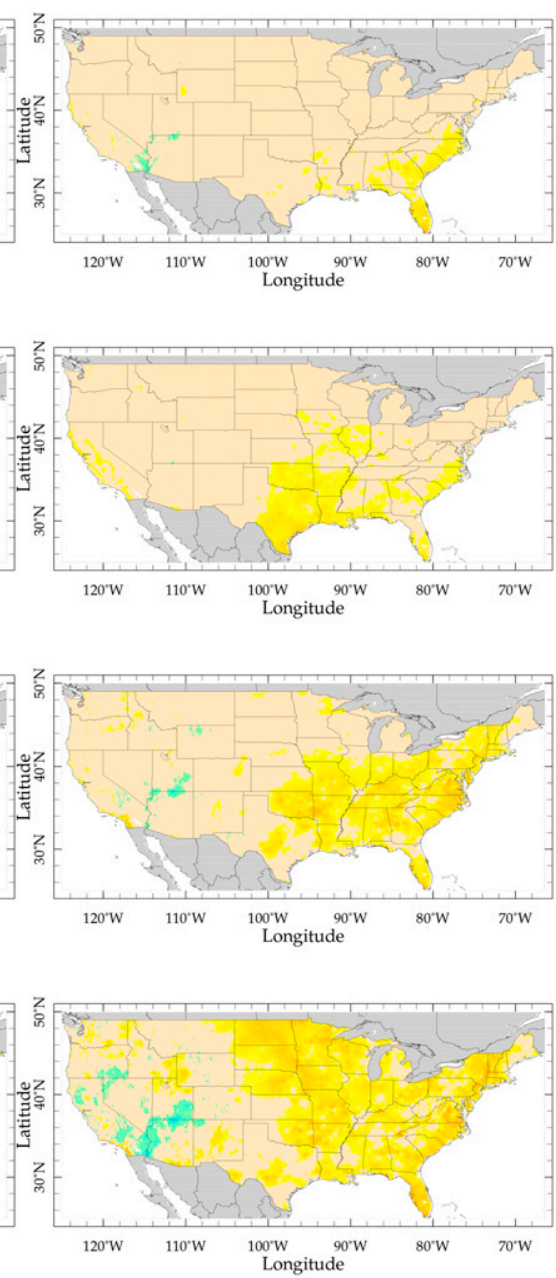

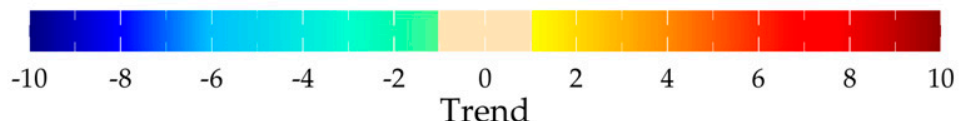

FIG. 9. Linear trends in VPD, $e_{s}$, and $e_{a}$ for 1960-2012/13 by season. Units are millibars of change over the 53-yr period.

conditions leading up to the July 2007 Murphy Complex fire in southern Idaho and northern Nevada. Unlike the other two fires, the Murphy Complex fire was a rangeland fire that burned a sagebrush ecosystem (Launchbaugh et al. 2008). It began after six smaller fires ignited by lightning combined, and it burned 263862 ha.

Figure 10 shows conditions during the previous winter, JFM 2002, in terms of standardized anomalies. Very high VPD was evident across the Southwest in JFM 2002 with maximum values in Arizona but not widespread in Colorado. Precipitation was below climatological normal across almost all of western North America. The Bowen ratio was high in the interior southwest in Arizona, New Mexico, and Colorado, consistent with a drier-than-normal land surface. Subsidence was also widespread across western North America occurring within northwesterly flow (as for the typical case of high Southwest VPD; Fig. 6). All of these prior winter conditions are conducive to elevating fire risk with both land surface and atmospheric drying being responsible. Figure 11 shows the same conditions for AMJ 2002. By spring high VPD anomalies had spread across the western United States centered on Arizona, New Mexico, Utah, and Colorado, reaching 3 standard deviations in most locations. Precipitation was also below normal by 2 or more standard deviations across the western United States and the Bowen ratio was elevated by 2 or more standard deviations across the Southwest. Unlike in the 
a) VPD

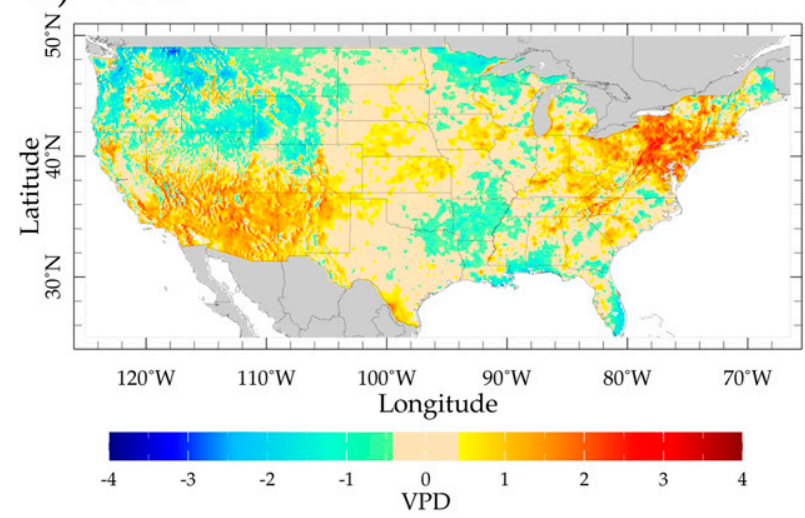

c) Bowen Ratio

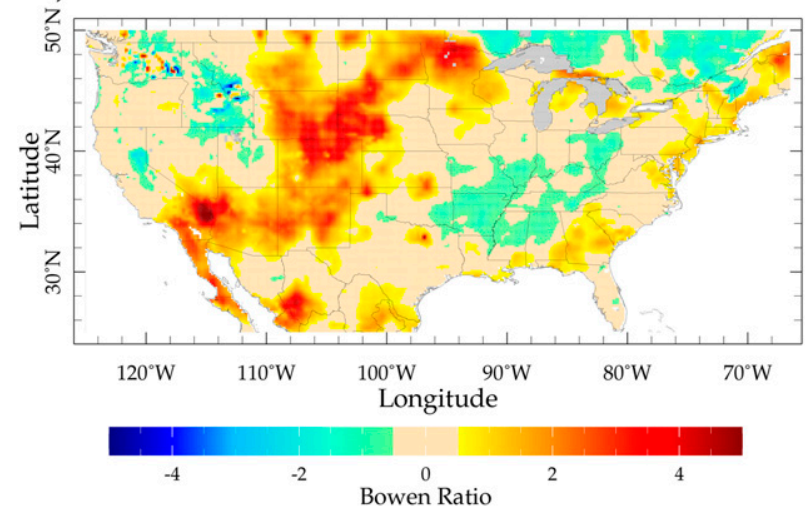

b) Precipitation

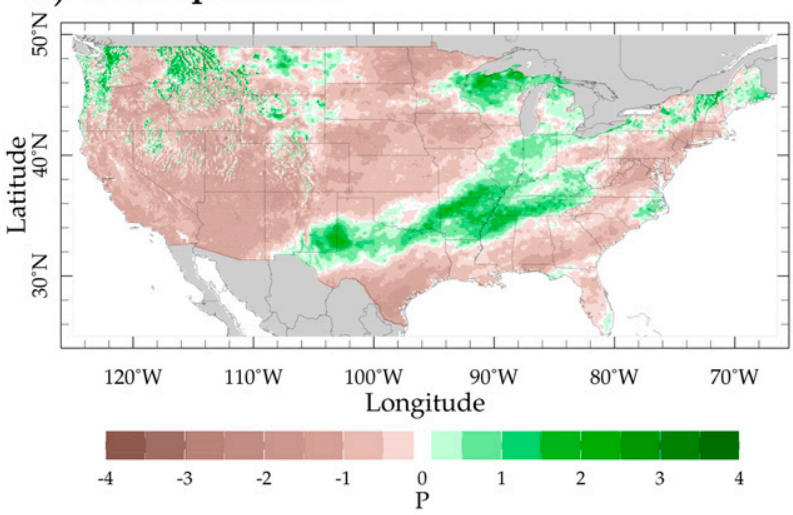

d) VV (color) Height (contours) $700 \mathrm{mb}$

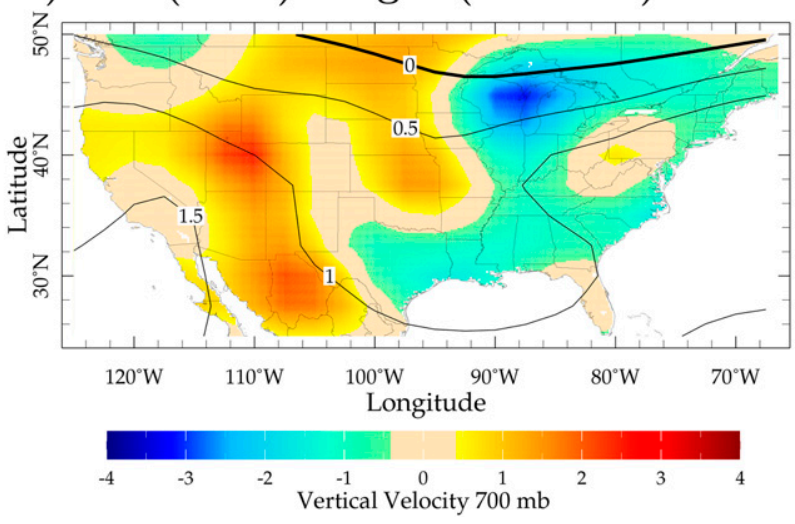

FIG. 10. Conditions in the winter before the Rodeo-Chediski and Hayman fires of June 2002. Shown for JFM 2002 are the standardized anomalies of (a) VPD, (b) precipitation, (c) Bowen ratio, and (d) 700-mb vertical pressure velocity (colors) and geopotential heights (contours).

previous season and the typical AMJ case for high VPD (Fig. 6), a southwesterly flow anomaly was associated with anomalous ascent. The precipitation, land surface conditions, and VPD state remained conducive to elevated fire risk as in the previous season. Consistent with the regression results in Fig. 8, conditions conducive for fire were influenced by both the atmospheric circulation and the land surface state in the seasons before.

Turning to the conditions before the Murphy Complex fire, in the previous late winter to spring (FebruaryApril 2007; Fig. 12) there was already a high VPD and a widespread, but not universal, negative precipitation anomalies across the West. The vertical velocity and pressure patterns are not remarkable and it is not clear what caused the high VPD anomaly other than the precipitation reduction. By spring to summer (Fig. 13) the vast area of high VPD had become intense and coincided with a nearly equally expansive area of very negative (about 2 standard deviations) precipitation anomalies. There was also a widespread positive Bowen ratio anomaly indicating drying out of the surface. All these anomalies encompassed the area of the Murphy Complex fire. The circulation anomaly was from the east with strong descending (drying) motion upstream of the fire area.

These relations, within the context of two specific historic forest fires, and one very large rangeland fire, support the idea of VPD exerting an influence on fire and also the influence of contemporary and prior atmosphere and land surface conditions on the VPD.

\section{Conclusions}

To our knowledge, this is the first comprehensive study of vapor pressure deficit, which was recommended by Anderson (1936) as a more useful measure of the moisture state of the atmosphere than relative humidity. Unlike $\mathrm{RH}$, for which the same value can be associated with very different moisture conditions depending on the air temperature, VPD is an absolute 


\section{a) VPD}

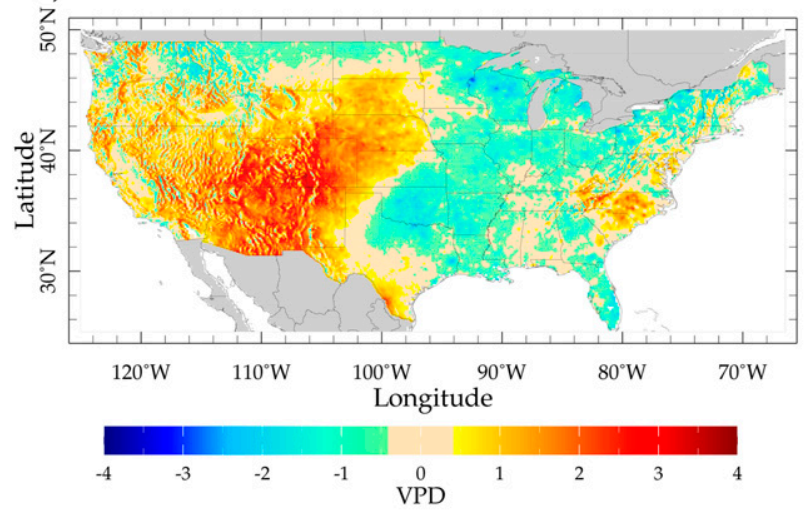

c) Bowen Ratio

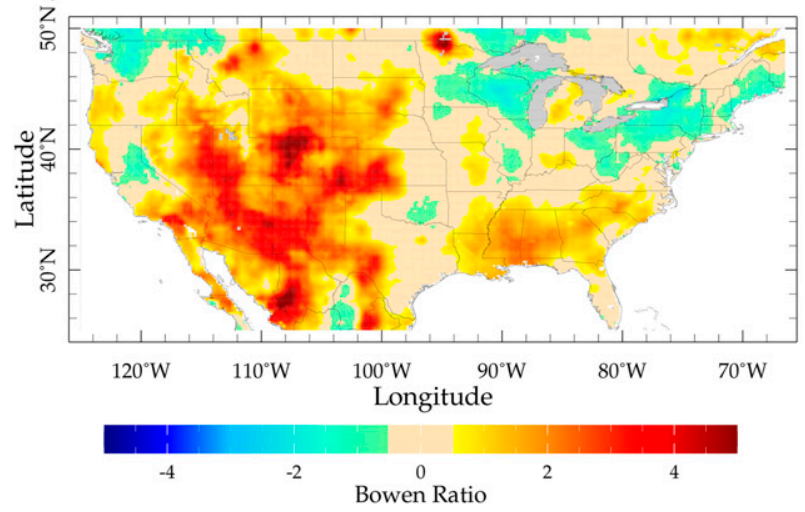

b) Precipitation

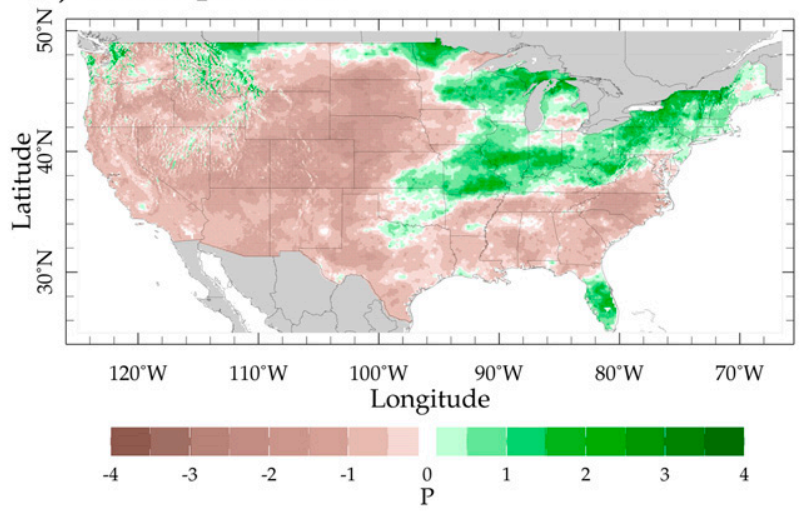

d) VV (color) Height (contours) $700 \mathrm{mb}$

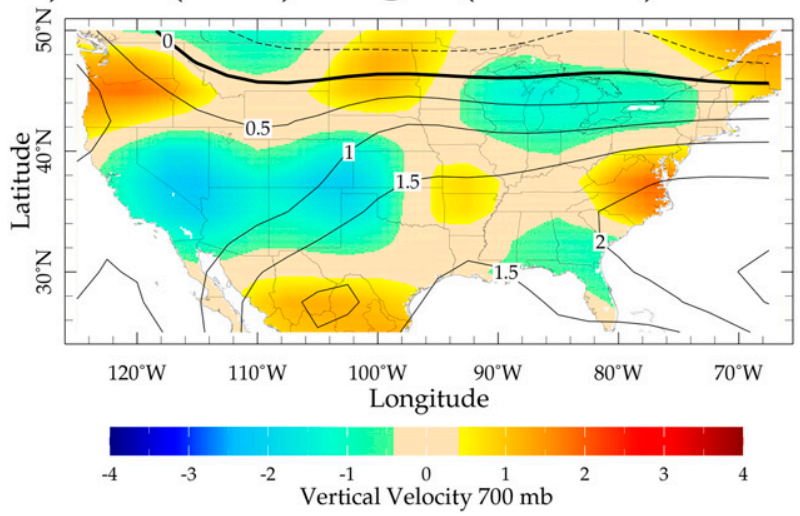

FIG. 11. As in Fig. 10, but for AMJ 2002.

measure of the moisture deficit of the atmosphere. Hence, VPD is more closely related to the water stress on vegetation. Prior work (Williams et al. 2015) and results presented here have shown the relationship between VPD variability and burned area in the southwest United States. That relation is the prime motivation for this study since it makes clear that a better understanding of the climatology, variability, and trends of VPD is needed.

- VPD follows a notable seasonal cycle with minimum values in the winter and maximum values in the summer. This is controlled by both the seasonal cycles of temperature and humidity. Because of the development of the subtropical anticyclones, which moisten the eastern United States and dry the western United States, actual vapor pressure has a summer maximum in the southeast but remains low in the west. In contrast, saturation vapor pressure in summer maximizes in the interior Southwest, southern and central plains, and the Southeast. Combining these influences, VPD in summer is far greater in the West than in the East. VPD reaches its all-U.S. maximum in summer at the California-Arizona border but more general maxima extend across the southwest United States.

- The variance of VPD has a minimum in fall and then strengthens into winter and then to spring and to summer. The Southwest and the southern plains stand out as maxima of variance in spring and summer. The VPD variance quite closely tracks the saturation vapor pressure variance but the Southwest and the southern plains are also regions of relatively strong variance of actual vapor pressure. Hence, it appears that VPD variability can be influenced by both thermodynamic and dynamic processes.

- High VPD in the interior southwest United States is associated with La Niña conditions in the tropical Pacific Ocean in fall, winter, and spring. This association works via ocean forcing of circulation anomalies that involve high pressure and northerly, subsiding flow over the Southwest. Such flow warms, increasing saturation vapor pressure, and 
a) VPD

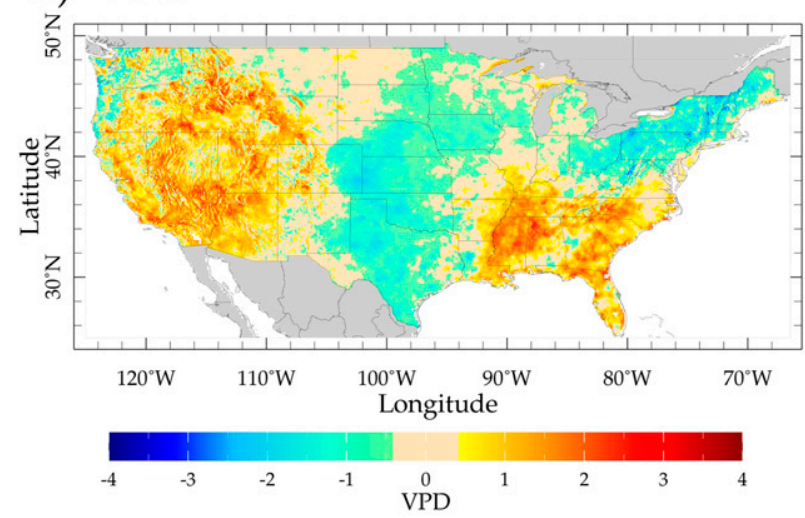

c) Bowen Ratio

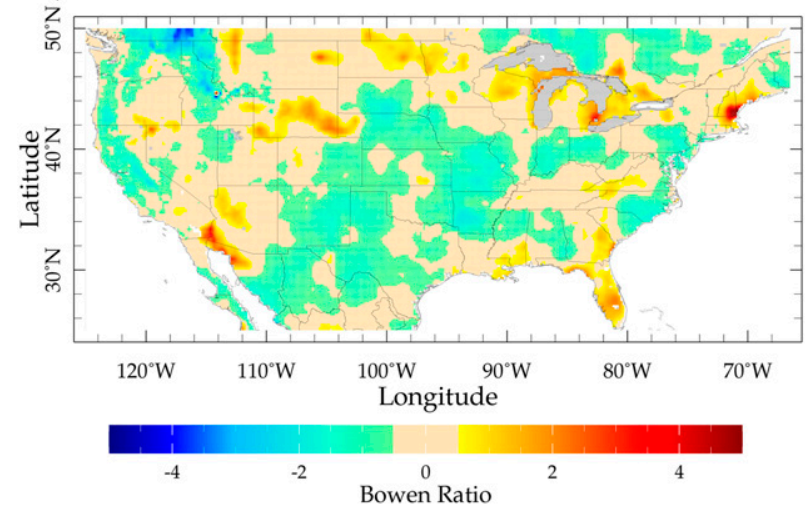

\section{b) Precipitation}

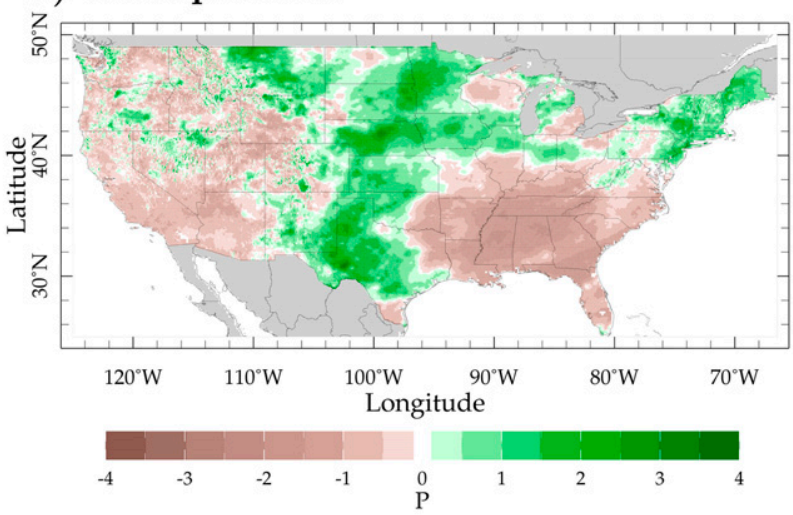

d) VV (color) Height (contours) $700 \mathrm{mb}$

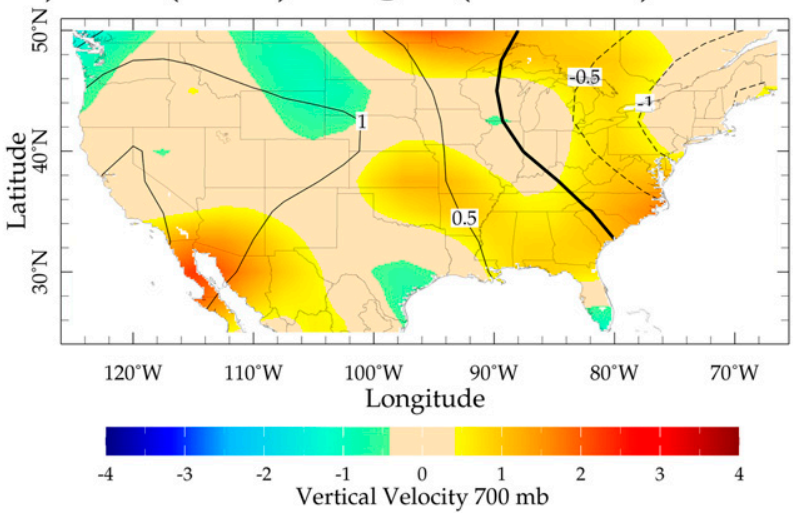

FIG. 12. As in Fig. 10, but for the Murphy Complex fire of July 2007 with February-April 2007 shown.

dries, decreasing actual vapor pressure, and, hence, causes VPD to increase. Summer VPD anomalies in the Southwest are controlled by more local circulation anomalies that influence saturation vapor pressure.

- High VPD in spring and summer can also be caused by an increase in Bowen ratio, that is an increase in sensible heat flux relative to latent heat flux, although the causes of this are distinct in the eastern and western United States. In the western United States, low surface moisture, following a drop in precipitation for example, can cause an increase in Bowen ratio and VPD.

- Case studies of conditions in advance of the June 2002 Rodeo-Chediski and Hayman fires in Arizona and Colorado, respectively, and the July 2007 Murphy Complex fire in southern Idaho-northern Nevada show very high VPD that was caused by precipitation drops, an increase in Bowen ratio, and anomalous subsidence in the preceding months. This reveals the complexity of meteorological processes that can increase drying of the land surface and vegetation and set the stage for serious fires.

- Since 1961, VPD has increased notably across the western United States with the strongest increases in the southwest. These trends have been primarily driven by warming that increases the saturation vapor pressure but have also been contributed to by a decrease in actual vapor pressure. Actual vapor pressure has increased elsewhere in the United States such that VPD has declined in the northern plains and the Midwest.

As an absolute measure of the difference between actual and potential water vapor holding capacity of the atmosphere, VPD is a useful indicator of the ability of the atmosphere to extract moisture from the land surface and, hence, is of relevance in studies of the links between meteorological conditions and wildland fires. Here, we have sought to achieve a basic understanding of the climatology and variability of VPD across the United States and have explained these in terms of atmospheric and land surface 


\section{a) VPD}

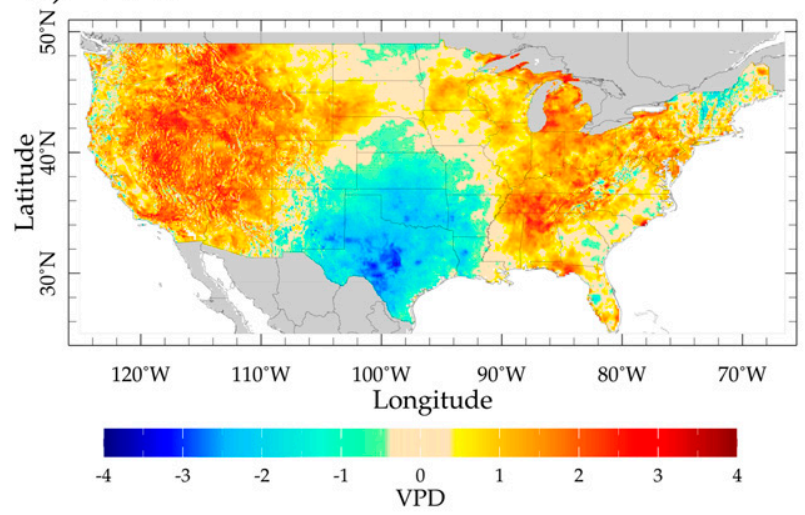

c) Bowen Ratio

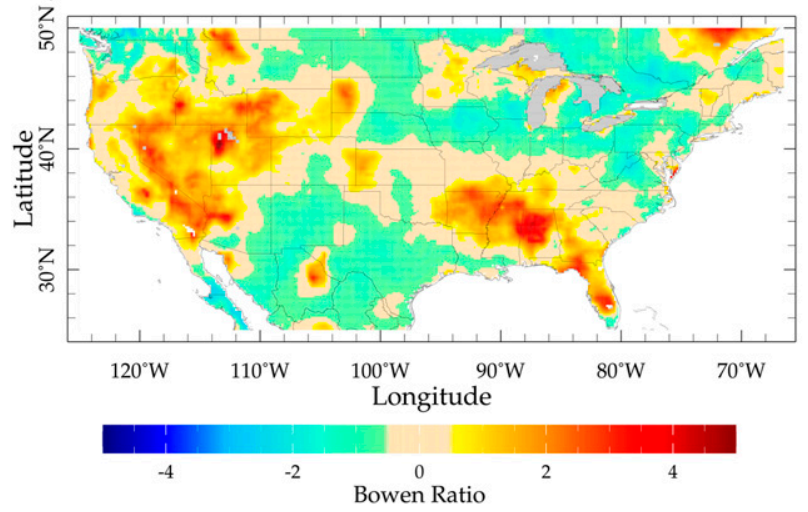

b) Precipitation

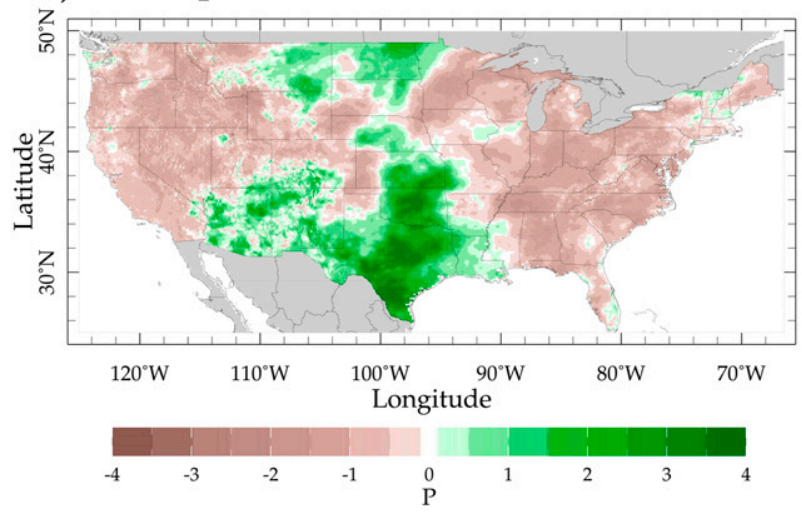

d) VV (color) Height (contours) 700mb

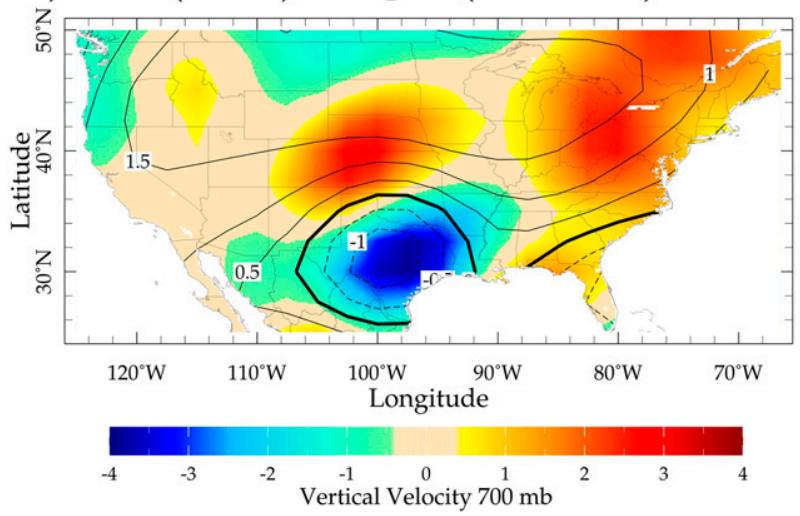

FIG. 13. As in Fig. 12, but for May-July 2007.

conditions. Future work will investigate closely the links between fires and VPD variability and the surface and atmospheric conditions that control them.

Monthly values of VPD, $e_{s}$, and $e_{a}$ for January 1960April 2013, as well as monthly climatologies, variances, and trends of these quantities can be accessed for visualization, analysis, and downloading online (http://kage. ldeo.columbia.edu:81/SOURCES/.LDEO/.ClimateGroup/ .DATASETS/.USVaporPressureData/).

Acknowledgments. This work was supported by NSF Award AGS-1243204 (Linking Near-term Future Changes in Weather and Hydroclimate in Western North America to Adaptation for Ecosystem and Water Management). Author AH was supported by an Earth Institute at Columbia University undergraduate research internship. The GLDAS data used in this study were acquired as part of NASA's Earth-Sun System Division and were archived and distributed by the Goddard Earth Sciences (GES) Data and Information Services Center (DISC) Distributed Active Archive Center (DAAC). We thank three reviewers for their helpful comments and criticisms.

\section{APPENDIX}

\section{Evaluation of Error Introduced into Vapor Pressure Calculations by Use of Monthly Mean Data}

To check the error involved in calculating $e_{s}, e_{a}$ and VPD from the data available in PRISM, we used the National Land Data Assimilation System (NLDAS) 3-hourly data for 1979-2012 (Mitchell et al. 2004). We computed $e_{s}, e_{a}$, and VPD using 3-hourly data and then averaged these results into monthly values. We then computed the monthly mean $T_{\max }, T_{\min }$, and $T_{d}$ and used the results to compute monthly mean $e_{s}$ and $e_{a}$. This was done for three disparate locations: Albuquerque, New Mexico, in the desert Southwest; Tallahassee, Florida, in the moist Southeast; and Minneapolis, Minnesota, in the continental northern interior. Results are shown in Fig. A1. The agreement is good. Using monthly means of $T_{\max }$ and $T_{\min }$ leads to a slight overestimation of $e_{s}$. There is no clear bias in estimating $e_{a}$ from monthly mean $T_{d}$ and, consequently, VPD is slightly overestimated using monthly mean data, most notably in the cooler continental climate of Minneapolis. However, the error is small. As such, since 


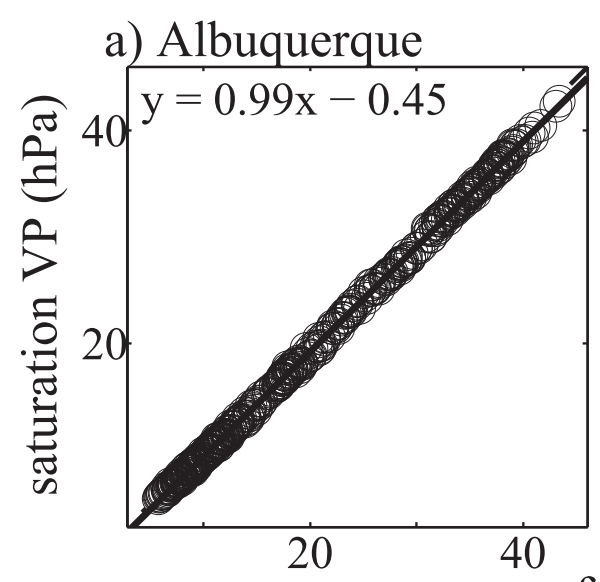

b) Tallahassee

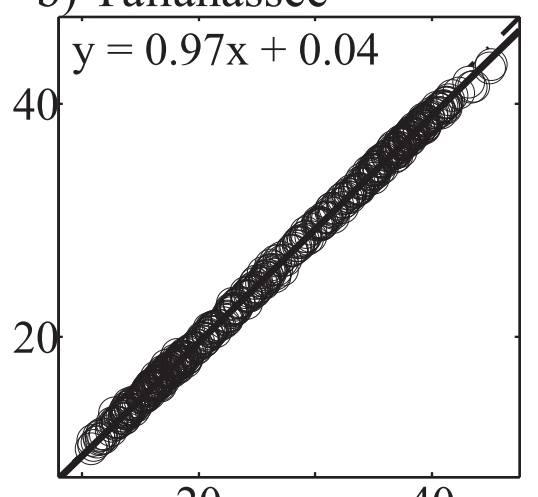

20

40 from monthly Tmax and Tmin c) Minneapolis

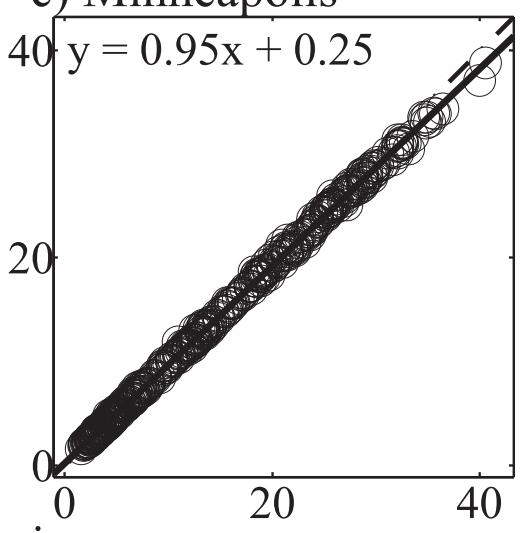

d) Albuquerque

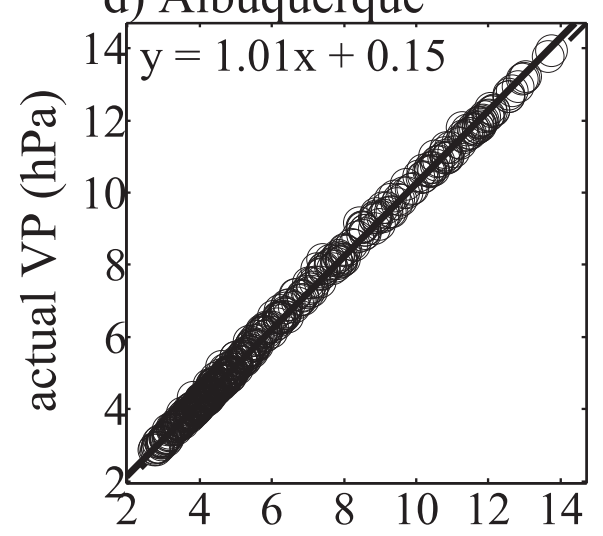

e) Tallahassee

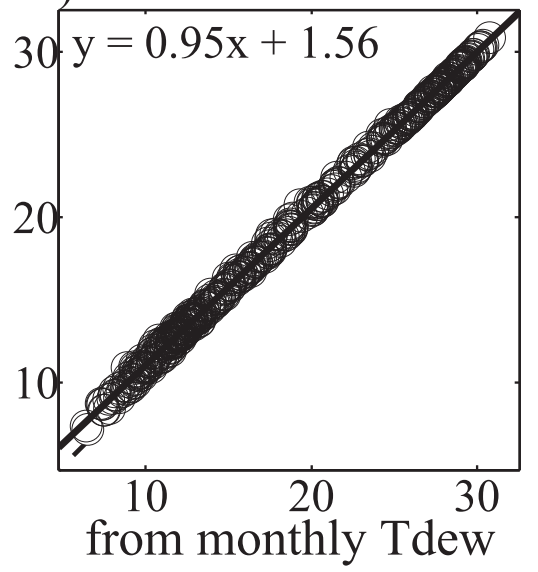

f) Minneapolis

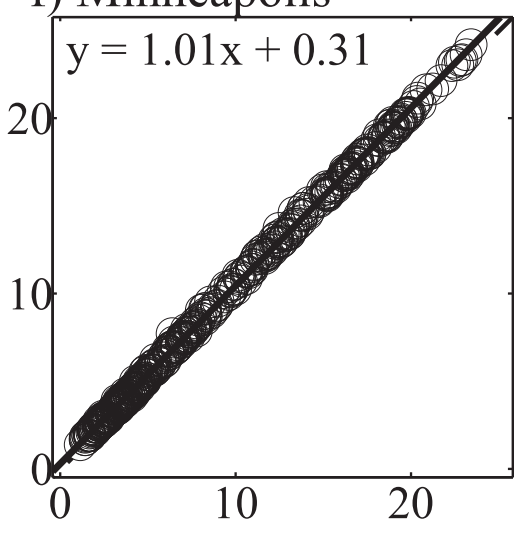

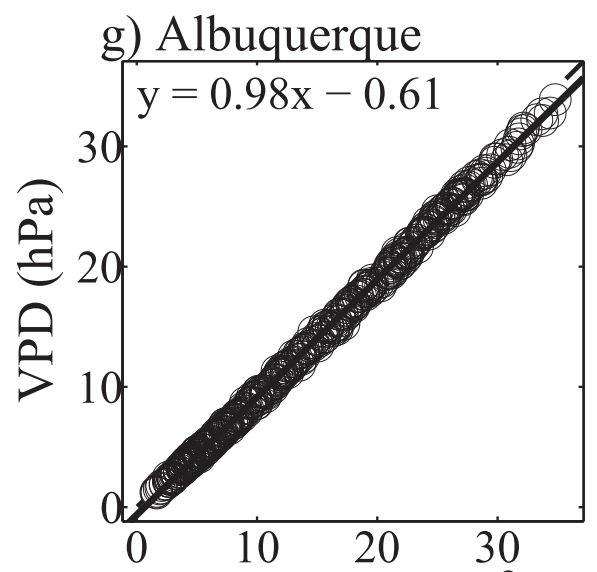

h) Tallahassee
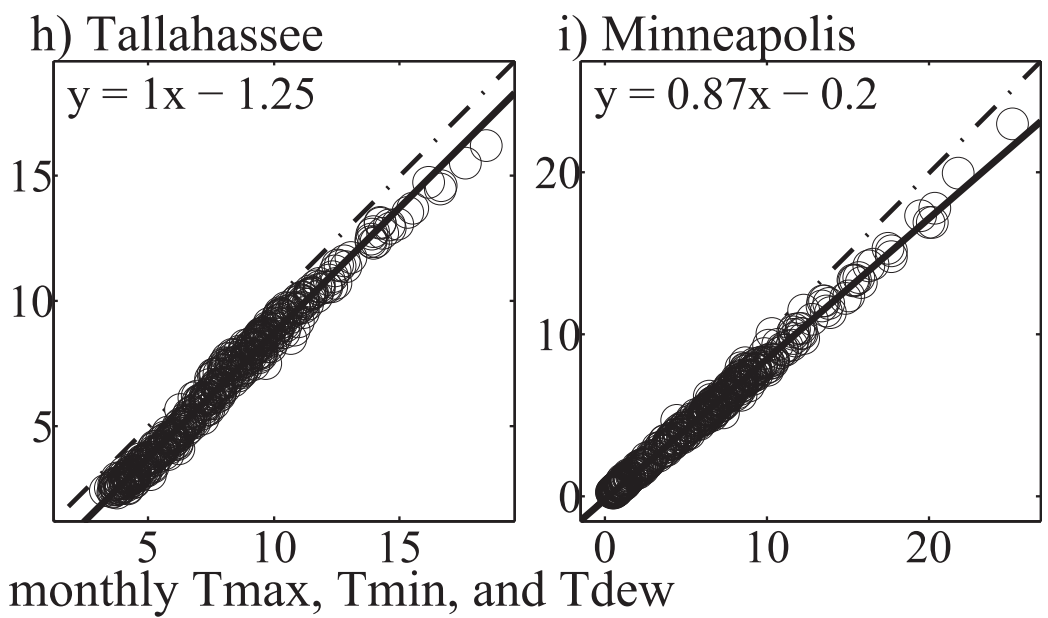

FIG. A1. Comparison of monthly mean (a)-(c) $e_{s}$, (d)-(f) $e_{a}$, and (g)-(i) VPD computed using 3-hourly data ( $y$ axis) and monthly mean $T_{\max }, T_{\min }$, and $T_{d}$ data ( $x$ axis) together with their linear least squares fit relations, all based on NLDAS data for 1979-2012. 
the NLDAS dataset begins in 1979, the decision was made to use the monthly data available in the PRISM dataset, which permits us to examine the longer period of 19612012, allowing an improved analysis of variability and trends of VPD, $e_{s}$, and $e_{a}$.

\section{REFERENCES}

Abatzoglou, J. T., and C. A. Kolden, 2013: Relationships between climate and macroscale area burned in the western United States. Int. J. Wildland Fire, 22, 1003-1020, doi:10.1071/WF13019.

Adams, D., and A. Comrie, 1997: The North American monsoon. Bull. Amer. Meteor. Soc., 78, 2197-2213, doi:10.1175/ 1520-0477(1997)078<2197:TNAM >2.0.CO;2.

Allen, C. D., and Coauthors, 2010: A global overview of drought and heat-induced tree mortality reveals emerging climate change risks for forests. For. Ecol. Manage., 259, 660-684, doi:10.1016/j.foreco.2009.09.001.

Anderson, D. B., 1936: Relative humidity or vapor pressure deficit. Ecology, 17, 277-282, doi:10.2307/1931468.

Bentz, B. J., and Coauthors, 2010: Climate change and bark beetles of the western United States and Canada: Direct and indirect effects. BioScience, 60, 602-613, doi:10.1525/bio.2010.60.8.6.

Cayan, D., T. Das, D. Pierce, T. Barnett, M. Tyree, and A. Gershunova, 2010: Future dryness in the southwest United States and the hydrology of the early 21 st century drought. Proc. Natl. Acad. Sci. USA, 107, 21 271-21 276, doi:10.1073/pnas.0912391107.

Daly, C., W. P. Gibson, G. H. Taylor, G. L. Johnson, and P. Pasteris, 2000: High quality spatial climate data sets for the United States and beyond. Trans. Amer. Soc. Agric. Biol. Eng., 43, 1957-1962, doi:10.13031/2013.3101.

Dennison, P. E., S. C. Brewer, J. D. Arnold, and M. A. Moritz, 2014: Large wildfire trends in the western United States, 1984-2011. Geophys. Res. Lett., 41, 2928-2933, doi:10.1002/ 2014GL059576.

Eidenshink, J., B. Schwind, K. Brewer, Z.-L. Zhu, B. Quayle, and S. Howard, 2007: A project for monitoring trends in burn severity. Fire Ecol., 3, 3-21, doi:10.4996/fireecology.0301003.

Gaffen, D. J., and R. J. Ross, 1999: Climatology and trends of U.S. surface humidity and temperature. J. Climate, 12, 811-828, doi:10.1175/1520-0442(1999)012<0811:CATOUS > 2.0.CO;2.

Gisborne, H. T., 1928: Measuring forest-fire danger in northern Idaho. U.S. Dept. of Agriculture Misc. Publ. 29, 63 pp.

Isaac, V., and W. A. van Wijngaarden, 2012: Surface water vapor pressure and temperature trends in North America during 19482010. J. Climate, 25, 3599-3609, doi:10.1175/JCLI-D-11-00003.1.

Kalnay, E., and Coauthors, 1996: The NCEP/NCAR 40-Year Reanalysis Project. Bull. Amer. Meteor. Soc., 77, 437-471, doi:10.1175/1520-0477(1996)077<0437:TNYRP>2.0.CO;2.

Kistler, R., and Coauthors, 2001: The NCEP-NCAR 50-Year Reanalysis: Monthly means CD-ROM and documentation. Bull. Amer. Meteor. Soc., 82, 247-268, doi:10.1175/ 1520-0477(2001)082<0247:TNNYRM > 2.3.CO;2.

Kumar, A., and M. P. Hoerling, 1998: Annual cycle of PacificNorth American seasonal predictability associated with different phases of ENSO. J. Climate, 11, 3295-3308, doi:10.1175/ 1520-0442(1998)011<3295:ACOPNA > 2.0.CO;2.

Launchbaugh, K., and Coauthors, 2008: Interactions among livestock grazing, vegetation type, and fire behavior in the Murphy Wildland Fire Complex in Idaho and Nevada, July 2007. U.S. Geological Survey Open-File Rep. 2008-1215, 42 pp. [Available online at http://pubs.usgs.gov/of/2008/1214/.]
Littell, J. S., D. McKenzie, D. L. Peterson, and A. L. Westerling, 2009: Climate and wildfire area burned in western U.S. ecoprovinces, 1916-2003. Ecol. Appl., 19, 1003-1021, doi:10.1890/ 07-1183.1.

Mitchell, K. E., and Coauthors, 2004: The multi-institution North American Land Data Assimilation System (NLDAS): Utilizing multiple GCIP products and partners in a continental distributed hydrological modeling system. J. Geophys. Res., 109, D07S90, doi:10.1029/2003JD003823.

Munns, E. N., 1921: Evaporation and forest fires. Mon. Wea. Rev., 49, 149-152, doi:10.1175/1520-0493(1921)49<149: $\mathrm{EAFF}>2.0 . \mathrm{CO} ; 2$.

Potter, B. E., 2012: Atmospheric interactions with wild land fire behavior-I. Basic surface interactions, vertical profiles and synoptic structures. Int. J. Wildland Fire, 21, 779-801, doi:10.1071/WF11128.

Pyne, S. J., 2009: Fire on the fringe. Environ. Res. Lett., 4, 031004, doi:10.1088/1748-9326/4/3/031004.

Riley, K. L., J. T. Abatzoglou, I. C. Grenfell, A. E. Klene, and F. A. Heinsch, 2013: The relationship of large fire occurrence with drought and fire danger indices in the western USA, 19842008: The role of temporal scale. Int. J. Wildland Fire, 22, 894 909, doi:10.1071/WF12149.

Rodell, M., and Coauthors, 2004: The Global Land Data Assimilation System. Bull. Amer. Meteor. Soc., 85, 381-394, doi:10.1175/ BAMS-85-3-381.

Roy, D. P., L. Boschetti, C. Justice, and J. Ju, 2008: The Collection 5 MODIS Burned Area Product-Global evaluation by comparison with the MODIS Active Fire Product. Remote Sens. Environ., 112, 3690-3707, doi:10.1016/j.rse.2008.05.013.

Schoennagel, T., T. T. Veblen, and W. H. Rome, 2004: The interaction of fire, fuels and climate across Rocky Mountain forest. BioScience, 54, 661-676, doi:10.1641/0006-3568(2004)054[0661: TIOFFA]2.0.CO;2.

Seager, R., 2007: The turn-of-the-century North American drought: Dynamics, global context, and prior analogues. J. Climate, 20, 5527-5552, doi:10.1175/2007JCLI1529.1.

_ N. Harnik, Y. Kushnir, W. Robinson, and J. Miller, 2003a: Mechanisms of hemispherically symmetric climate variability. J. Climate, 16, 2960-2978, doi:10.1175/1520-0442(2003)016<2960: MOHSCV $>2.0 . \mathrm{CO} ; 2$.

—, R. Murtugudde, N. Naik, A. Clement, N. Gordon, and J. Miller, 2003b: Air-sea interaction and the seasonal cycle of the subtropical anticyclones. J. Climate, 16, 1948-1966, doi:10.1175/ 1520-0442(2003)016<1948:AIATSC >2.0.CO;2.

—, N. Harnik, W. A. Robinson, Y. Kushnir, M. Ting, H. P. Huang, and J. Velez, 2005: Mechanisms of ENSO-forcing of hemispherically symmetric precipitation variability. Quart. J. Roy. Meteor. Soc., 131, 1501-1527, doi:10.1256/qj.04.96.

— L L. Goddard, J. Nakamura, N. Naik, and D. Lee, 2014a: Dynamical causes of the 2010/11 Texas-northern Mexico drought. J. Hydrometeor., 15, 39-68, doi:10.1175/JHM-D-13-024.1.

- D. Neelin, I. Simpson, H. Liu, N. Henderson, T. Shaw, Y. Kushnir, and M. Ting, 2014b: Dynamical and thermodynamical causes of large-scale changes in the hydrological cycle over North America in response to global warming. J. Climate, 27, 7921-7948, doi:10.1175/JCLI-D-14-00153.1.

Sedano, F., and J. T. Randerson, 2014: Vapor pressure deficit controls on fire ignition and fire spread in boreal forest ecosystems. Biogeosci. Discuss., 11, 1309-1353, doi:10.5194/bgd-11-1309-2014.

Sheffield, J., and G. G. E. Wood, 2006: Development of a 50-yr highresolution global dataset of meteorological forcings for land surface modeling. J. Climate, 19, 3088-3111, doi:10.1175/JCLI3790.1. 
Stavros, E. N., J. Abatzoglou, N. K. Larkin, D. McKenzie, and E. A. Steel, 2014: Climate and very large wildland fires in the contiguous western USA. Int. J. Wildland Fire, 23, 899-914, doi:10.1071/WF13169.

Stephens, S. L., J. K. Agee, P. Z. Fule, M. P. North, W. H. Romme, T. W. Swetnam, and M. G. Turner, 2013: Managing forests and fire in changing climates. Science, 342, 41-42, doi:10.1126/ science.1240294.

Weiss, J. L., C. L. Castro, and J. T. Overpeck, 2009: Distinguishing pronounced droughts in the southwestern United States: Seasonality and effects of warmer temperatures. J. Climate, 22, 5918-5932, doi:10.1175/2009JCLI2905.1.

Westerling, A. L., and B. P. Bryant, 2008: Climate change and wildfire in California. Climatic Change, 87 (Suppl.), 231-249, doi:10.1007/s10584-007-9363-z.

, A. Gershunov, T. J. Brown, D. R. Cayan, and M. D. Dettinger, 2003: Climate and wildfire in the western United States. Bull. Amer. Meteor. Soc., 84, 595-604, doi:10.1175/ BAMS-84-5-595.
—_, H. G. Hidalgo, D. R. Cayan, and T. W. Swetnam, 2006: Warming and earlier spring increase western U.S. forest wildfire activity. Science, 313, 940-943, doi:10.1126/ science.1128834.

Williams, A. P., and Coauthors, 2013: Temperature as a potent driver of regional forest drought stress and tree mortality. Nat. Climate Change, 3, 292-297, doi:10.1038/nclimate1693.

_ , and Coauthors, 2014: Causes and future implications of extreme 2011 atmospheric moisture demand and wildfire in the southwest United States. J. Appl. Meteor. Climatol., 53, 26712684, doi:10.1175/JAMC-D-14-0053.1.

— , and Coauthors, 2015: Correlations between components of the water balance and burned area reveal new insights for predicting forest-fire area in the southwest United States. Int. J. Wildland Fire, 24, 14-26, doi:10.1071/WF14023.

Winkler, J. A., B. E. Potter, D. Wilhelm, R. P. Shadbolt, K. Piromsopa, and X. Bian, 2007: Climatological and statistical characteristics of the Haines index for North America. Int. J. Wildland Fire, 16, 139-152, doi:10.1071/WF06086. 